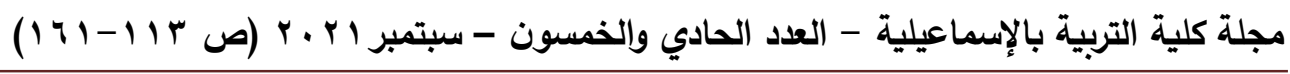

السعادة الذاتية وعلاقتها بالثعور بالتماسك لاى طالبات الجامعة إعداد

د. هانم مصطفى محمد مصطفى البرعي

مقدمة الدراسة:

تلعب الحالة النفسية للفرد دورا هاما في حياته، ومستوى الابداع، والانجاز الأى يؤديه في

ظل مستويات الحالة النفسية، ففي حين تؤدى المستويات المرتفعة من الثعور بالسعادة الى دلى دادئ

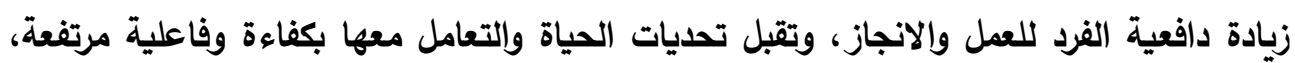
يكون سبب الاخفاق في العديد من المواقف وجود مستوى منخفض من هذا الثعور لاى الفرد، يعوقه عن التفكير بشكل سوى حينما يتعرض لمشكلات الحياة، لذا كان اهتمام الباحثين في علم النفس الإيجابي في الآونة الاخيرة بدراسة مثل هذه المتغيرات التي اثبتت الدراسات فاعليتها في

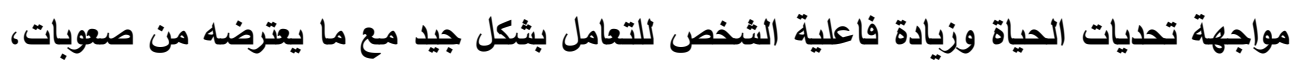
كما انها احدى مؤشرات الثعور بالصحة النفسية. ولعل دراسة مستوى السعادة الذاتية لاى طلاب الجامعة من المحاولات الهامة في مجال الصحة النفسية للتعرف على إمكانات الطلاب النفية في مواجهة الأزمات بمرحلة الثباب. Happiness \& وبمراجعة دراسات السعادة يلاحظ استخدام مصطلحين للتعبير عن السعادة Well being

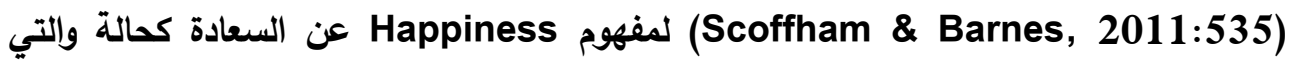
يصل إليها الفرد من خلال إثباع الاحتياجات والنجاح، بينما يشير المصطلح الثاني للسعادة والذي يوصف بإنه الأعم بكونه الهاف الذي يسعى الفرد للحصول عليه من الحياة، ويعنى في بعض معاجم اللغة العربية بالرفاهة. لذا فقد حاول العديد من الباحثين دراسة مفهوم السعادة للوقوف على أنواعها وأبعادها

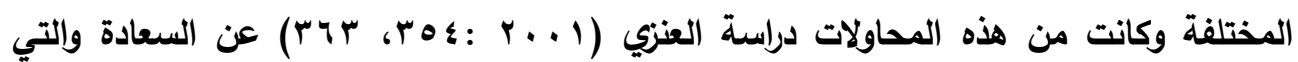
عرف فيها المفهوم بأنه" حالة من التوازن الداخلي يسودها عدد من المشاعر الايجابية

*مدرس الصحة النفسية ، كلية التربية جامعة قناة السويس وجامعة الملك فيصل. 
السعادة الأتية وعلاقتها بالثعور بالتماسك ------ د/ هانم مصطفى محمد مصطفى البرعي

كالرضا، والابتهاج، والسرور والتي ترتبط بالجوانب الاساسية للحياة مثل الاسرة، والعمل،

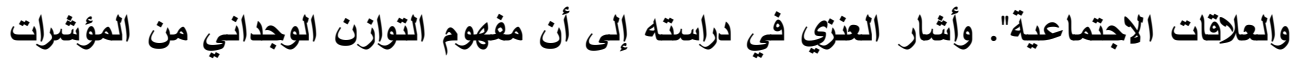

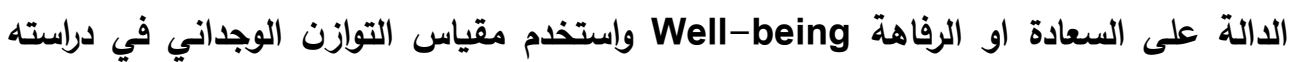
لقياس مستوى الثعور بالسعادة.

بينما ميزت دراسة شين واخرون(Chen et al., 2012) بين نوعين من السعادة هما السعادة الذاتية والنفسية Psychological and Subjective Well-Being وان لكل درعل منهما (بعاده المختلفة. ونظرا لأهمية هذا المفهوم في الصحة النفسية للفرد اهتم كثير من الباحثين بدراسة هذه المفهوم في علاقته بالعديد من المتفيرات الثخصية والاجتماعية، وكنلك المتغيرات النفسية والمعرفية، في محاولة لمعرفة المتغيرات ذات التأثير المباشر وغير المباشر، والمتغيرات الوسيطة ذات العلاقة بهذا المفهوم، ومن هذه المتفيرات التدفق Flow وهى "حالة تعد كخبرة مثلى تحدث للفرد من وقت لآخر عذدما يؤدى اقصى درجات الاداء حيث يقضى فيها الفرد وقته ويمارس فيها

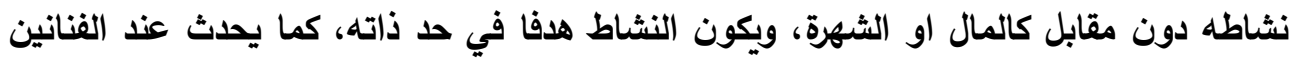

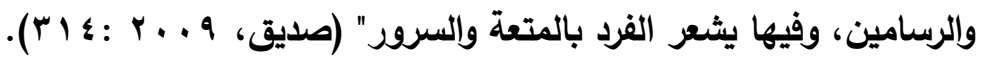
ويعد التفكير الإيجابي من المتغيرات الاخرى التي اهتم بها الباحثون في مجال علم النفس الإيجابي، والتي أشارت العديد من الدراسات الى ارتباطها بالثعور بالسعادة. ويذكر سوينسون (Swinson, 1996) الأثياء الجيدة في حياته، كما يتوقع السعادة والنجاح، ويجد المتعة في أداء كل عمل، كما لإيجا

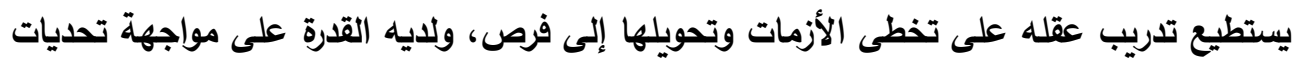

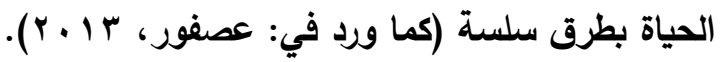

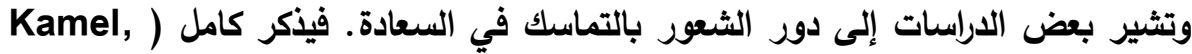
2001) ان الثعور بالتماسك Feeling of Coherence يلعب دور المصدات في الثعور بالسعادة، أي كلما ارتفع الثعور بالتماسك كلما قل تأثير الخبرات السلبية على الفرد وارتفع لايه مستوى الثعور بالسعادة النفسية. وبمراجعة الدراسات السابقة والادبيات في مجال دراسة السعادة الذاتية لاى طلاب الجامعة والعوامل المرتبطة به، نجد أن هناك حاجة للمزيد من الدراسات المهتمة بمتغير السعادة الذاتية 


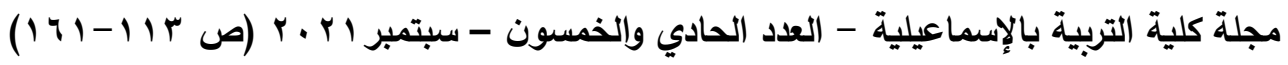
في المجال العزبي لاى طلبة الجامعة، لذا تسعى الدراسة الحالية للتوصل الى العلاقة بين بالسعادة الذاتية والثعور بالتماسك لدى طالبات الجامعة. مشكلة الدراسة:

تعد دراسة الخصائص النفسية الإيجابية لطلاب الجامعة من الدراسات الهامة في مجال علم النفس الإيجابي، ونظرا لحاجة هذا المجال لإجراء العديد من الدراسات على الفئات المختلفة لتحديد العوامل ذات الصلة والارتباط بالمتغيرات المرتبطة بالشعور بالصحة النفسية، والفروق بين الفئات المختلفة حول هذه المتغيرات، لذا كان الاهتمام بلراسة السعادة الذاتية لطالبات الجامعة كأحد متغيرات هذا المجال وعلاقته بالشعور بالتماسك، وبمراجعة الدراسات المنشورة حتى عام

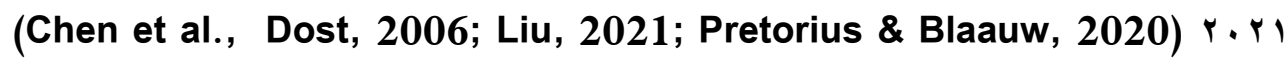
2012;

طلاب الجامعة، وتحاول الاراسة الحالية الإجابة على التساؤلات التالية:

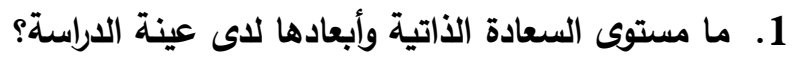

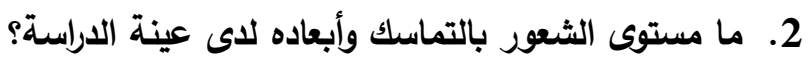

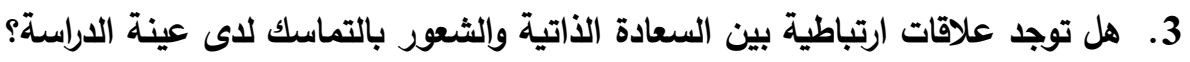
4. هل يوجد تأثير لكل من المستوى الاراسي والتخصص والحالة الاجتماعية والتفاعلات الثنائية بينهما على السعادة الأتية وأبعادها؟ 5. هل يوجد تأثير لكل من المستوى الاراسي والتخصص والحالة الاجتماعية والتفاعلات الثنائية والثلاثية بينهم على الثعور بالتماسك وأبعاده؟ 6. ما مدى إسهام الثعور بالتماسك بالسعادة الأتية لاى عينة الدراسة؟ باله أهداف الدراسة:

تتمثل أهداف الدراسة الحالية فيما يلي: 1. التعرف على مستوى السعادة الذاتية وأبعادها لاى عينة الدراسة. 2. التعرف على مستوى الثعور بالتماسك وأبعاده لاى عينة الدراسة. 3. الكثف عن تأثير بعض المتغيرات الديموغرافية (المستوى الدراسي والتخصص والحالة الاجتماعية) على السعادة الذاتية وابعادها لاى عينة الدراسة. 4. الكثف عن تأثير بعض المتفيرات الديموغرافية (المستوى الدراسي والتخصص والحادهالة الاجتماعية) على الثعور بالتماسك وأبعاده لاى عينة الدراسة. 
السعادة الأتية وعلاقتها بالثعور بالتماسك ------ د// هانم مصطفى محمد مصطفى البرعي

5. التعرف على طبيعة العلاقة الارتباطية بين السعادة الذاتية والثعور بالتماسك لاى عينة

الاراسة.

6. تحديد مدى اسهام الثعور بالتماسك بالسعادة الذاتية لاى عينة الدراسة.

أهمية الدراسة:

الأهمية النظرية:

1. تعد الدراسة الحالية إسهاما في مجال الدراسات الخاصة بعلم النفس الإيجابي، نظرا لندرة

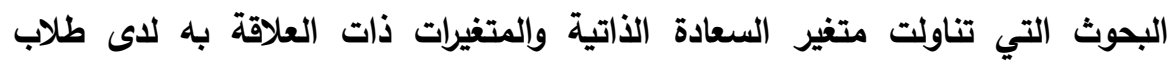

الجامعة.

2. تثري الاراسة الحالية المجال المعرفي من خلال تعريب وتقنين مقياسي السعادة الذاتية

والثعور بالتماسك لطلاب الجامعة والتي يمكن استخدامها على نطاق واسع في الوطن

العربي.

3. تسهم نتائج الدراسة الحالية في اجراء المزيد من الدراسات للكثف عن علاقة السعادة

الأتية بالعديد من المتغيرات النفسية والمعرفية لتحقيق التكامل في الثعور بالصحة الثرية

النفسية لاى طلاب الجامعة.

الأهمية التطبيقية:

1. الكثف عن مستوى السعادة الذاتية والثعور بالتماسك لاى طلاب الجامعة لما لهذه

المتغيرات من تأثير إيجابي على الإنجاز والفاعلية والكفاءة الثخصية والمهنية.

2. تثري نتائج الدراسة الحالية في الكشف عن مدى اسهام الشعور بالتماسك بالسعادة

الأتية للتخطيط للبرامج الارشادية اللازمة لتحسين مستوى هذا الثعور لاى طلاب

الجامعة.

مصطلحات الاراسة:

1. السعادة الذاتية Subjective well-Being

يعرف كل من رينشو وبولينينو (Renshaw \& Bolognino, 2016: 464)

السعادة الذاتية بأنها "مزيج من مكونات انفعالية، ومعرفية، واجتماعية، وسلوكية، تفسر وبرلئر

كيف يشعر الناس، ويفكرون، ويتواصلون، ويتصرفون، والتي تعبر عن تقيمهر عن

بعض الموضوعات كالرضا عن الحياة، والكفاءة الأتية، والمثابرة، والمشاعر الإيجابية". 


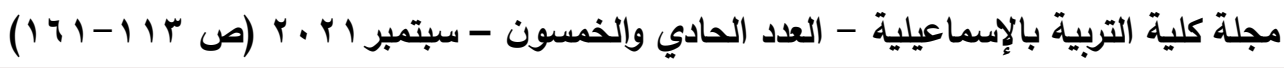

2. الشعور بالتماسك:Feeling of Coherence

يعرف انتونوفيسكى (9^v 1 ) الثعور بالتماسك أنه "الطريقة التي ينظر بها الشخص الى العالم الخارجي والتي تيسر التوافق الناجح مع المحن، وذلك من خلال المرونة والقدرة على الاستجابة مع الضغوط، لذا فالثعور بالتماسك يعد كحلقة الوصل بين الصحة النفسية والثعور بالضغط". ويرى أنتونوفسكي أن هذا الثعور يتألف من ثلاث أبعاد وهي:

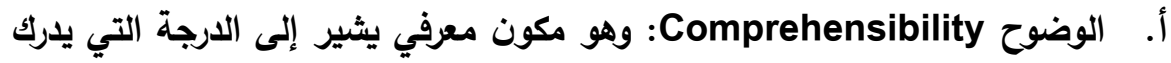
بها الفرد المعلومات والبيئة الاجتماعية في مفاهيمها، ومحتواها، وبنائها، ومتطلباتها. ب. قابلية الإدارة Manageability: وهو مكون أدائي يشير الى الدرجة التي يشعر فيها الفرد بامتلاك المصادر المطلوبة بثكل كافِ لتلبية احتياجاته الداخلية والخارجية. ج. فهم المعنى Meaningfulness: وهو مكون تحفيزي يشير الى المدى الذى يشعر فيه الفرد بوجود مواقف في الحياة تستحق ان يسخر لها الفرد الوقت والجها

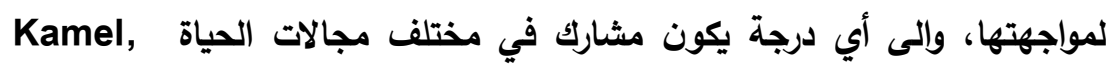
.(2001:77-78)

الإطار النظري والدراسات السابقة:

أولا السعادة الذاتية:

اهتم الباحثون في الآونة الاخيرة بدراسة موضوعات علم النفس الإيجابي، والتي أطلقها

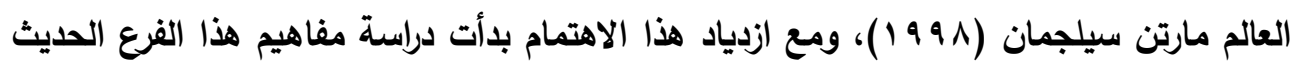
من علم النفس تستقطب جهود الباحثين في كل مكان لتحديد مفاهيمها والوقوف على العوامل ذات العلاقة بها.

ويعد مفهوم السعادة الذاتية من المفاهيم الحديثة في دراسات السعادة والذى تباينت آراء الباحثين في المفهوم واختلافه عن مفهوم السعادة النفسية. يثير كل من كيز وشيموتكن وريف ديف دائ (Keyes, Shmotkin, \& Ryff, 2002 ) (Kashdan, Diener, \& King, المتمايزة عن الأخر، بينما يرى كاشدان ودينر وكينج (2008 ان المفهومان متشابهان أكثر من كونهما مختلفان، وأثثارت نتائج دراسة شين وآخرون 
السعادة الأتية وعلاقتها بالثعور بالتماسك ------ د/ هانم مصطفى محمد مصطفى البرعي

(Chen et al., 2012) أحدهما السعادة النفسية والأخر السعادة الذاتية، ويتبع البعد الأول (السعادة النفسية) اربع عوامل نوعية، بينما يتبع البعد الثاني (السعادة الذاتية) ثلاث عوامل نوعية، كما توجد علاقة قوية بين الإدئ

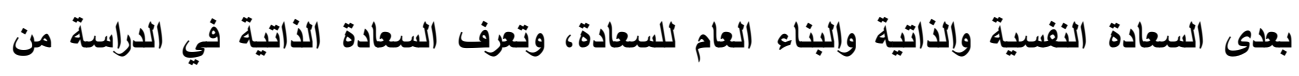
منظور المتعة والتي تحقق الثعور بالسعادة والسرور في الحياة، بينما تعبر السعادة النفسية عن

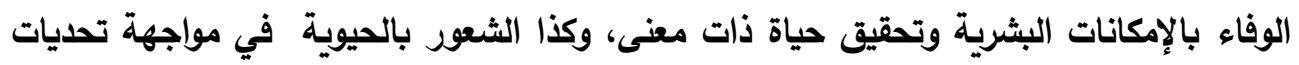

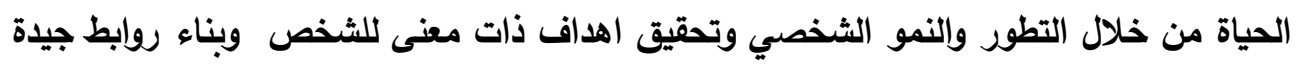
مع الأخرين من مناه ويعد نموذج رايف (1989, Ryff) للسعادة النفسية من أكثر النماذج استخداما في بناء مقاييس السعادة النفسية والذي يتكون من ستة عوامل هى (الاستقلال الذاتي، والتمكن البيئي،

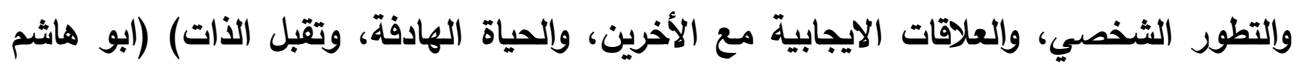

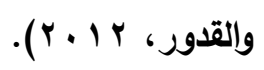

ولعل القارئ في مفهوم السعادة الاتية Subjective Well-being يجد تباين في تعريب المفهوم ففي حين يستخدم الفنجرى (Y. . . P) المفهوم بنفس الترجمة الحالية السعادة

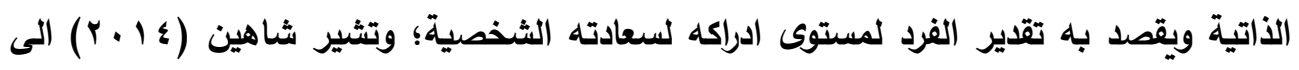
المصطلح الرفاهة الأتية كترجمة للمفهوم وتعنى به تقييمات الثخص المعرفية والوجدانية لنوعية

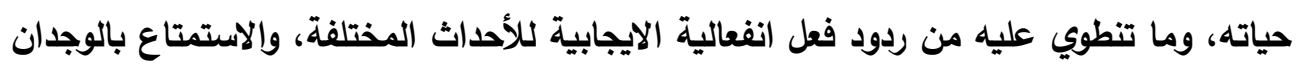
الإيجابي، والتحرر من الوجدان السلبي فضلا عن الناتج المعرفي للشعور بالرضا والاشباع. وقد استخدمت الباحثة في الدراسة الحالية مفهوم السعادة الذاتية بوصفه مكمل لمفهوم السعادة النفسية الثائع الاستخدام في الدراسات العربية والاجنبية والذي يتكامل معه المكون العام للسعادة Chen et al., 2012; Keyes, Shmotkin, \& Ryff, 2002)Well being

$$
\text { نظريات الستري، V . . ץ). }
$$

مدخل المتعة Hedonic approach

اشار دينر (Diener, 1984) في نموذجه للسعادة الذاتية الى ان السعادة الذاتية عبارة عن مستوى مرتفع من الثعور بالمتعة في المزاج والعاطفة، مع الثعور بلرجة منففضة من 


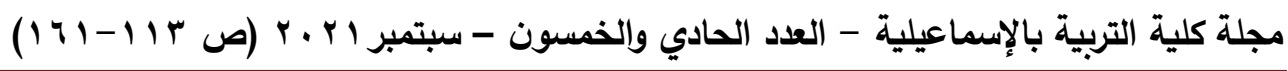

المشاعر السلبية في العاطفة والمزاج، والشعور بالرضا عن الحياة بدرجة مرتفعة. Chen et)

al., 2012)

Eudaimonic approach مدخل الكفاية

يركز رين وديسى (Ryan \& Deci, 2001 في هذا المدخل على المعنى وتحقيق الذات

Cited ) وتعريف السعادة في الحالة التي يعمل فيها الشخص بشكل كامل self-realization

.(In: Tomas, Sancho, Melendez, \& Mayordomo, 2011)

قياس السعادة الذاتية:

تعددت رؤية الباحثين لأبعاد السعادة الذاتية فالبعض يشير إلى مفهوم السعادة الذاتية

كاتجاه إيجابي للحياة يشعر فيه الفرد بالسعادة Happiness، والرضا عن الحياة والروح المعنوية والإيجابية المرتفعة، وفي هذا الاتجاه تتكون أبعاد السعادة الذاتية من ثلاث ابعاد هي التأثير الإيجابي، والتأثير السلبي، والرضا عن الحياة (Litwin \& Ezra, 2010:380). وقد وضع واطسون وآخرون (Watson et al., 1988) مقياس التأثير الإيجابي والسلبي يتكون من هr عبارة تثتمل على مقياسين الأول مقياس التأثير الإيجابي ويتضمن الأبعاد التالية (النشاط، اليقظة، الانتباه، الإصرار، الحماس، التشوق، الإلهام، الاهتمام، الفخر، القوة)، بينما اشتمل مقياس التأثير السلبى على أبعاد (الخوف، الخجل، الاكتئاب، الثعور بالذنب، العدائية،

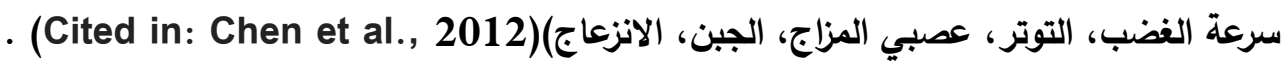
ويعبر بربد بيزن Bradburnعن التأثير السلبي والإيجابي بالوجدان الإيجابي والسلبي، فالفرد المتمتع بدرجة مرتفعة في السعادة الذاتية يكون نتيجة ارتفاع درجته في الوجدان الإيجابي

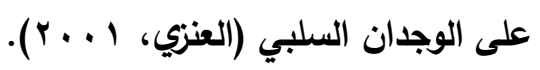
السعادة الذاتية وعلاقتها ببعض المتغيرات:

وبمراجعة الدراسات التي أجريت في مجال السعادة الذاتية وعلاقتها بمتغيرات أخرى، اشارت

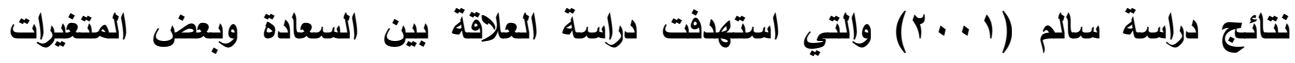
النفسية، ودراسة الفروق في مستوى الثعور بالسعادة عبر المراحل العمرية المختلفة (طلاب دابه الثانوي - طلاب الجامعة ) من الجنسين، أشارت الدراسة في نتائجها إلى وجود فروق ذات ذات دلالة احصائية في مستوى الثعور بالسعادة في المراحل العمرية المختلفة عند الجنسين لصالح الذكور

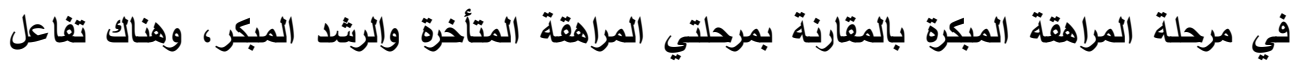
مشترك بين العمر والجنس في مستوى الثعور بالسعادة. 
السعادة الأتية وعلاقتها بالثعور بالتماسك ------ د/ هانم مصطفى محمد مصطفى البرعي

وفي دراسة عبد الخالق وآخرون (r . . . T) والتي استهدفت الدراسة قياس معدلات السعادة

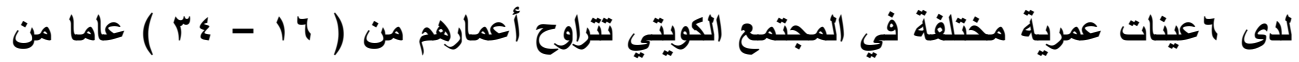
الجنسين في الفئات ( طلاب الثانوي - طلاب الجامعة - موظفين ) وطبقت عليهم قائمة اوكسفورد للسعادة لأرجيل، دلت نتائج الدراسة على وجود فروق ذات دلالة احصائية في متوسطات درجات السعادة لصالح الذكور بالمقارنة بالإناث، وكانت فئة الموظفين من الذكور هم الاكثر شعورا بالسعادة، كما اشارت نتائج الدراسة الى وجود تأثير مشترك للتفاعل بين الجنس والعمر في متغير السعادة.

ويلخص دوست (Dost, 2006:190) بعض العوامل ذات العلاقة بالسعادة الذاتية،

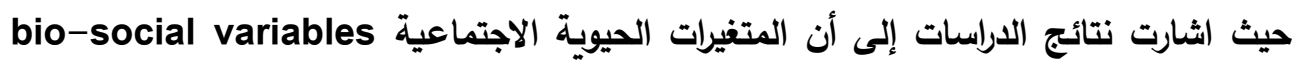

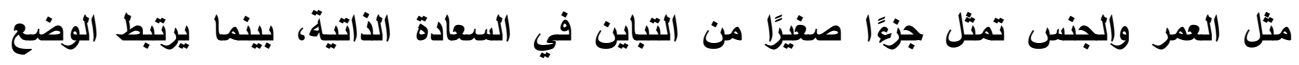
الاجتماعي والاقتصادي ارتباطًا وثيقًا بالسعادة الذاتية، وقد يكون الدخل والوضع الاجتماعي من فن أقوى العوامل التي تنبئ بالسعادة الذاتية.

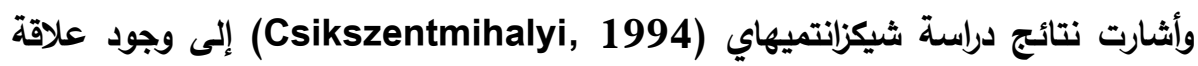
بين التدفق والسعادة تحدث بسبب نشاط التركيز والاندماج الكامل وتحقيق النجاح. وهو ما دلت دأت عليه دراسة كاربنتر وآخرون (Carpentier et al., 2011) والتي استهدفت بحث العلاقة بين خبرة التدفق والثعور بالسعادة لاى عينات من البالغين يشعرون بحالات من الانسجام العاطفي لهاتي ودلت النتائج انه كلما كانت الحالة أكثر ميلا للانسجام العاطفي كانت خبرة بالتدفق أكثر في لباني

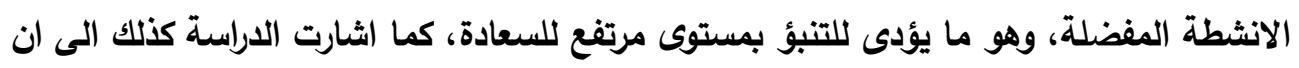
الثعور بالحالة الرومانسية والتدفق ذات علاقة ايجابية بالسعادة. بينما اشارت دراسة دافيز (Davies, 2009) وإلتي استهدفت التعرف على تأثير التفكير الإيجابي وتقدير الذات كنموذج تفسيري في السعادة الوجدانية، وذلك على عينة من الطلاب المراهقين، الى وجود تأثير فعال للتفكير الإيجابي على تحقيق السعادة الوجدانية عند المراهقين.

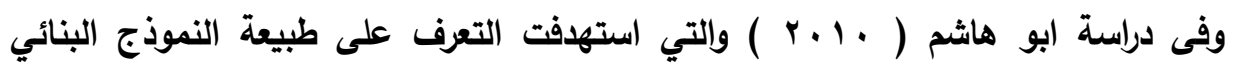
للعلاقات بين السعادة النفسية والعوامل الكبرى للشخصية وتقدير الذات والمساندة الاجتماعية لاى الى طلاب الجامعة، والتي تكونت من ه . ؛ طالب وطالبة بكلية التربية الى عدم وجود فروق دالة احصائيا بين متوسطات درجات الأكور والاناث في السعادة النفسية بمكوناتها الفرعية، مع وجود علاقات ارتباطية متباينة النوع ( موجبة - سالبة ) والدلالة (دالة - غير دالة) بين درجات 


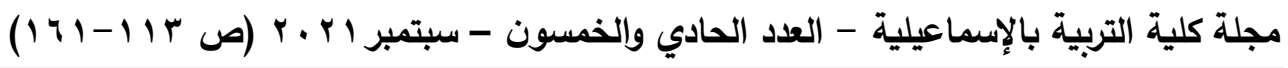
الطلاب في السعادة النفسية بمكوناتها الفرعية وكل من العوامل الكبرى للشخصية وتقدير الذات

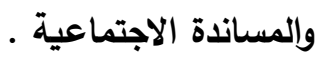

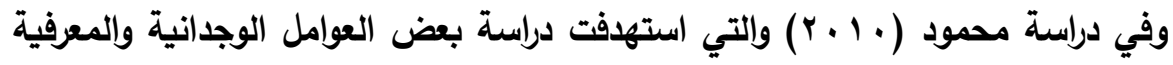

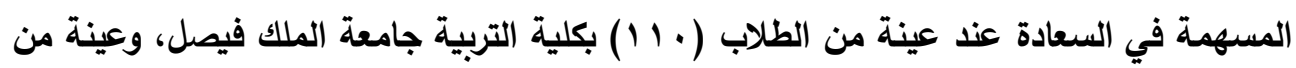
المعلمين ( 9 9) بالمدارس الاهلية، أشارت نتائج الدراسة الى وجود ارتباط دال إيجابي بين التفكير

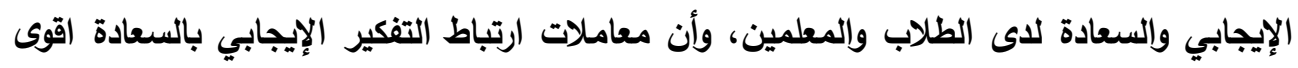

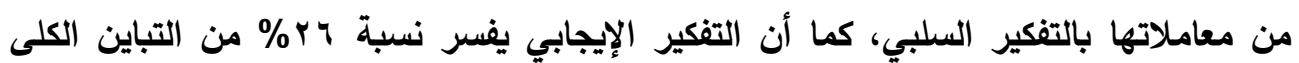
للوجدان الإيجابي.

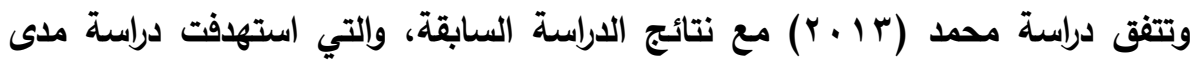
فاعلية برنامج تدريبي لتنمية التفكير الإيجابي لاى عينة من معلمات مرحلة رياض الاطفال تقدر ب ( • (r) معلمة ودراسة تأثير ذلك على جودة الحياة، توصلت الدراسة إلى أن تنمية التفكير

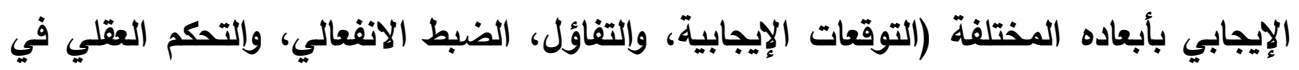
الانفعال، والتقبل الإيجابي للاختلاف عن الآخرين، وتقبل المسؤولية الثخصية والاجتماعية،

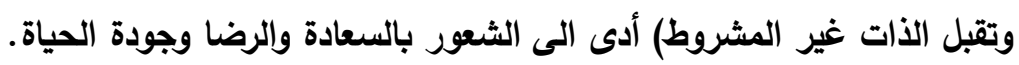

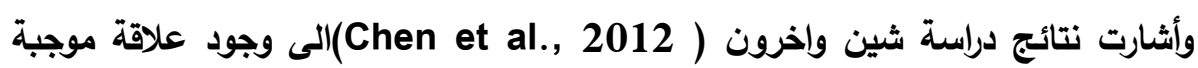
بين السعادة الذاتية والشعور بالتفاؤل وجودة العلاقات، وتحسين الذات، وتقدير الذات، بينما توجد علاقة عكسية بين السعادة الأتية واعراض الاكتئاب. واستخلصت دراسة بريتوريوس وبلاو (Pretorius \& Blaauw, 2020) التي أجريت على طلاب جنوب إفريقيا بالسنة الأولى الجامعية، ان هؤلاء الطلاب يواجهون العديد من التحديات التي قد تؤثر على تصوراتهم الذاتية لرفاهيته وسط مستويات عالية من الاتحار والاكتئاب، وتوصلت الدراسة الى ان المتغيرات المتعلقة بترتيبات المعيشة، والمتغيرات التي لهات لهات

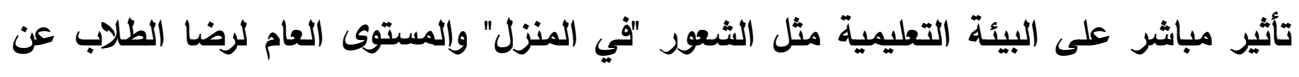
تجربة الجامعة تؤثر بثكل إيجابي في السعادة الذاتية للطلاب، بينما المتغيرات السلبية التي تؤثر

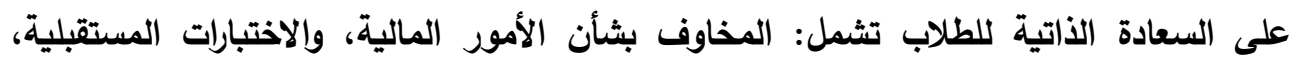
والعيش في الحرم الجامعي أو على مسافة قرببة من الحرم الجامعي.

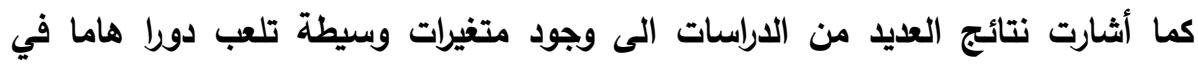
شعور طلاب الجامعة بالسعادة الذاتية. فقد توصلت دراسة وانغ (Wang, 2020) التي أجربيت 
السعادة الذاتية وعلاقتها بالثعور بالتماسك ------ د/ هانم مصطفى محمد مصطفى البرعي

على 1 ؛ ط طالب جامعي بالصين، حيث دلت نتائج نموذج المعادلة البنائية الى ان سمة الامتنان

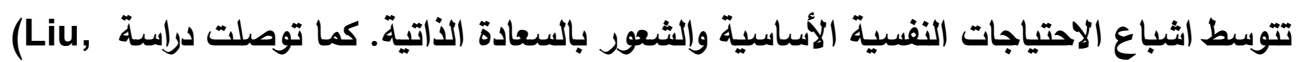
(2021 الى دور المساندة الاجتماعية في الثعور بالسعادة الذاتية، حيث تقوم بدوراً وسيطا بين متغيرات التسامح للذات، والتسامح بين الأثخاص، والسعادة الذاتية لاى طلاب الجامعة. يتضح من نتائج الاراسات السابقة:

- وجود علاقات ارتباطية موجبة بين الثعور بالسعادة الذاتية والعديد من المتغيرات

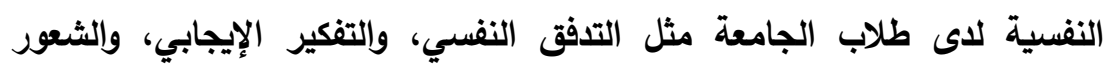
بالتفاؤل وجودة العلاقات، وتحسين الأت، وتقدير الذات، والثعور بالرضا عن الحياة الجامعية، والتسامح. - - تقوم بعض المتغيرات بدور وسيط في الثعور بالسعادة الأتية لاى طلاب الجامعة كالمساندة الاجتماعية، والشعور بالامتنان. - - توجد علاقة عكسية بالاكتئاب، وبعد المسافة عن الجامعة، وضعف الحالة المالية، والمخاوف من الاختبارات. - - توجد فروق ذات دلالة احصائية في الثعور بالسعادة الذاتية بين الذكور والاناث، وبين المراحل العمرية المختلفة، وق اجريت هذه الدراسات على مراحل عمرية وفئات مختلفة كطلاب الجامعة والمراهقين والمعلمين. ثانياً الثعور بالتماسك: يثير انتونوفنكي (Antonovsky,1979) مؤسس نظرية الثعور بالتماسك، إلى استخدام النظرية على نطاق واسع لتفسير رؤية الافراد لمفهومهم عن البيئة بثكل ذو معنى، لوني،

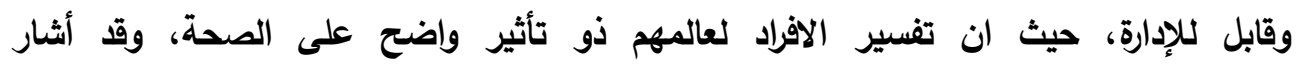
انتونوفيسكي إلى العديد من العوامل المسهمة في ارتفاع مستوى الثعور بالتماسك لاى الفرد

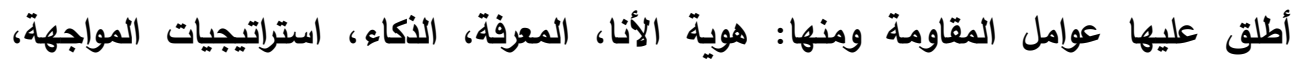
المساندة الاجتماعية، الالتزام، الاستقرار الثقافي، الجاذبية، الفلسفة، الدين، التوجهات الصحية الصاية الوقائية، ويرى انتونوفيسكي ان هذه العوامل تتشكل من خبرات الحياة التي تتميز بالاتساق - (Eriksson \&Lindstrom, 2017, 460) والاتزان يعرف انتونوفيسكي (9^^1 ( الشعور بالتماسك انه مدى شعور الفرد بالثقة في تفسير

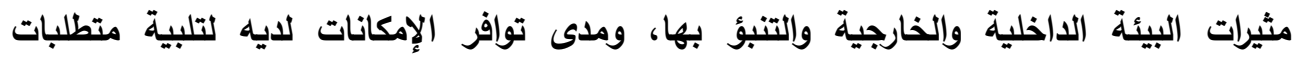




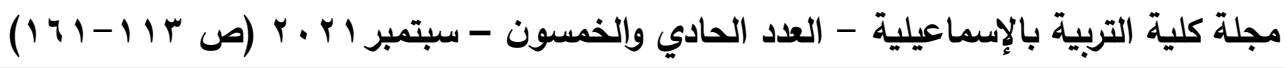
واحتياجات هذه البيئة والتي تعد كتحديات تستحق البحث والعمل. ويعتبر انتونوفيسكي أن هذا المفهوم يتكون من ثلاث مكونات فرعية هي الثعور بالفهم؛ والثعور بالإدارة؛ والثعور بالمعنى، والتي يرتبط كلا منها بالآخر، والتي تثكل في مجملها الثعور بالتماسك، وبالرغم من أهمية البيئة إلا أنه لا يوجد دليل قوي على أن أحداث الحياة السلبية قد تقلل من مستوى الثعور

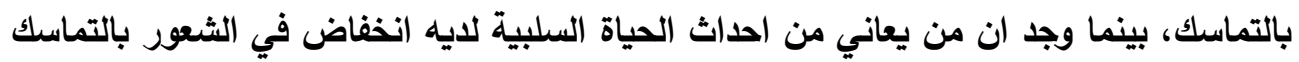

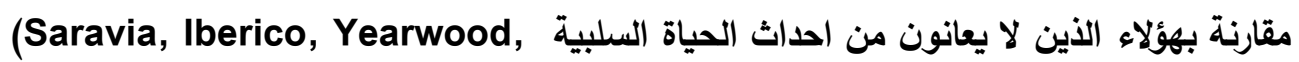
$.2014,35)$

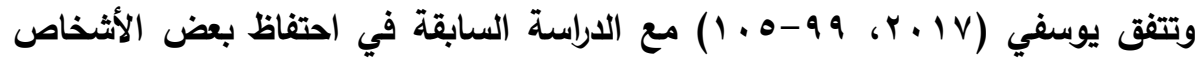
بصحتهم النفسية والجسدية رغم معايشتهم لظروف بيئية شديدة وضاغطة مقارنة لآخرين عاشوا نفس الظروف، يعود لارتفاع مستوى الثعور بالتماسك بمكوناته الثلاث (الوضوح، قابلية الإدارة،

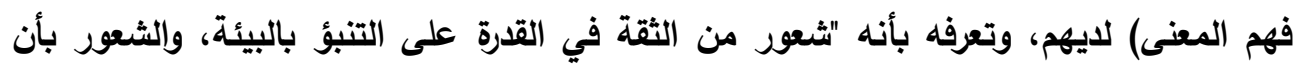
الأمور ستسير على أفضل ما يكون". ويتضمن الأمور التالية:

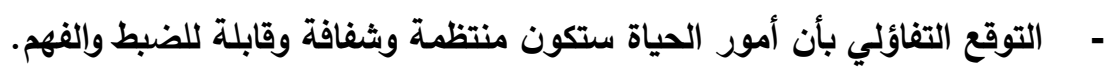
- - الثقة بأنه سيتم السيطرة على الأحداث الحياتية المستقبلية من خلال الجهود الذاتية أو من خلال الدعم والمساندة الخارجية. - القناعة الفردية المتمثلة بأن الأحداث المستقبلية عبارة عن مطالب أو مهمات ستطرح على الفرد، وأن الأمر يستحق أن يضحي في سبيلها. وقد اشارت نتائج العديد من الدراسات الى دور الثعور بالتماسك في الاسهام النسبي

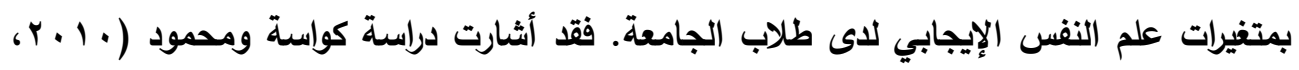

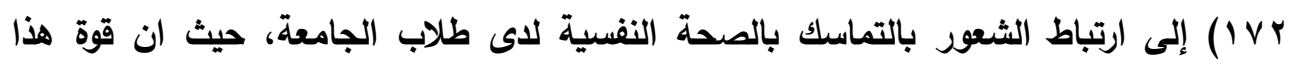

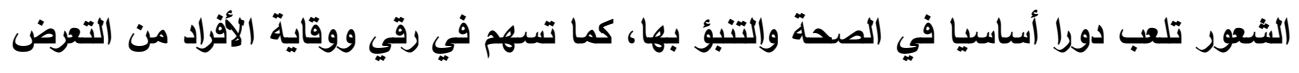

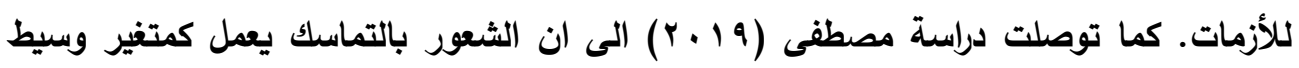

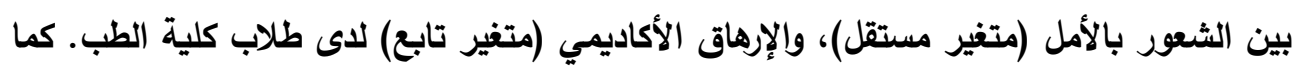

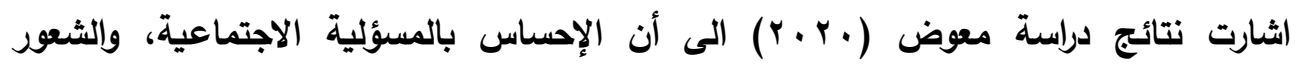
بالتماسك قد أسهما بنسبة (r, ؛ ٪\%) في تباين جودة الصداقة لاى طلاب الدراسات العليا. وتثير بانتوزا وآخرون (Pantuza et al., 2019) الى علاقة الشعور بالتماسك بالخوف من التحدث في الأماكن العامة، فالطلاب الذين أبلغوا عن عدم خوفهم من التحدث في بانتون 
السعادة الذاتية وعلاقتها بالثعور بالتماسك ------ د/ هانم مصطفى محمد مصطفى البرعي

الأماكن العامة كانوا اكثر شعور بالتماسك، ولايهم تقييم ذاتي إيجابي بشكل مرتفع، وهو ما يوضح أهمية الثعور بالتماسك كمصدر مهم للتوافق نظرًا للتدخل الكبير للجوانب العاطفية في

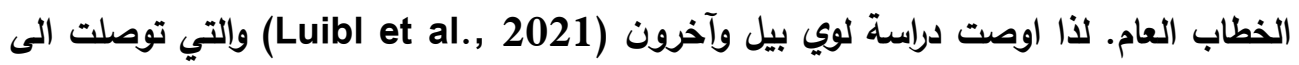
وجود علاقة بين الضغوط النفسية والاكتئاب لطلاب الجامعة بمتغيرات الشعور بالتماسك

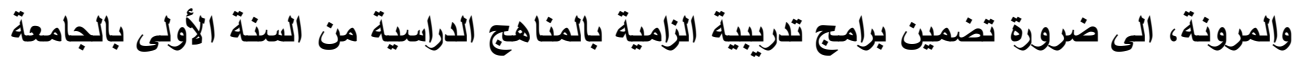
وحتى التخرج، تعمل على حماية الصحة النفسية للطلاب. ويرى انتونوفيسكي (9^v) (1 أن توقعات الفرد عن الحياة بقابليتها للفهم، والإدارة، وأنها

ذات معنى تجعل الفرد أكثر تطورا ونشاطا وتكيفا خاصة عندما يتعامل مع الضغوط. (Bowman, 1996, 547) واسع في المجالات الطبية والتقييمات النفسية، من خلال تقييم توجهات الفرد ونقاط قوته الاخلية، والتي تففر مدى نجاح الفرد في التكيف مـع الضغوط، وهذا التوجه يسعى لشرح الأسباب التي تجعل الفرد يتجه نحو الصحة، وهو توجه نقيض النموذج الطبي والذي يركز بشكل كبير على العوامل المسهمة في المرض (Jakobsson, 2011, 6). العلاقة بين السعادة والشعور بالتماسك: يلعب الثعور بالتماسك دور أساسي في الوظائف النفسية، حيث دلت العديد من الدراسات إلى أن الثعور بالتماسك بدرجة كبيرة يؤدى الى درجات مرتفعة من التكيف والمرونة. فقد اشارت دراسة كامل (Kamel, 2001) والتي استهافت الاجابة على التساؤل الآتي: هل الثعور بالتماسك يعد عامل وسيط بين الخبرات السلبية والسعادة النفسية عند البالغين؟ استخدم الباحث مقياس الثعور بالتماسك انتونوفيسكى (9 1 العلى عينة من البالغين تقدر

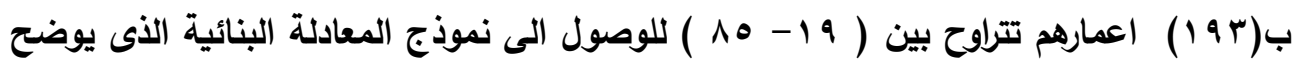
قيم الارتباطات بين متغيرات الدراسة، ودلت نتائج الدراسة على أن الثعور بالتماسك له دور واضح في الوظائف النفسية بثكل عام وخاصة في الصحة النفسية، واتضح ذلك من خلال مسارات الارتباطات بين الخبرات السلبية والثعور بالسعادة والتي كانت دالة في المجموعات الضعيفة في الثعور بالتماسك، وعلى العكس كاتت المسارات غير دالة مع المجموعات التي يرتفع فيها الثعور بالتماسك، وهذا يدل على أن الثعور بالتماسك يلعب دور المصدات في

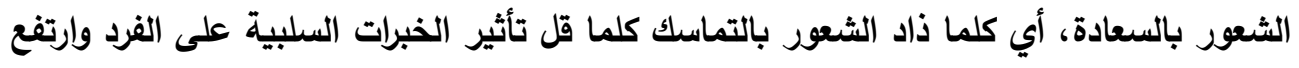
لايه مستوى الثعور بالسعادة النفسية. 


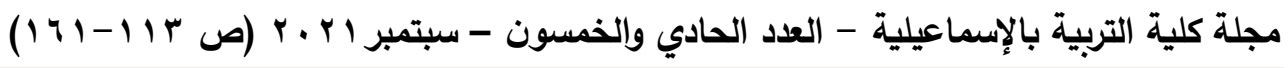

واتفقت دراسة اولسون وآخرون (Olsson et al., 2008) مع نتائج الاراسة السابقة،

والتي استهدفت دراسة العلاقة بين الشعور بالتماسك والسعادة لاى عينة من آباء الأطفال المعاقين عقليا وغير المعاقين قبل سن دخول المدرسة، وأشارت نتائج الدراسة إلى وجود علاقة ارتباطية موجبة دالة احصائيا بين مستوى الثعور بالسعادة والثعور بالتماسك حيث كان مستوى الشعور بالسعادة والتماسك منخفض لاى آباء الأطفال ذوي الإعاقة العقلية في مواقف الحياة الاجتماعية والاسرية مقارنة بآباء الاطفال غير المعاقين.

كما دلت نتائج دراسة هوارد (Howard, 2008) والتي استهرفت دراسة مداء ماءى إسهام متغيرات علم النفس الإيجابي (كالتدفق، الثعور بالتماسك، وكفاءة الذات، إدارة العمل، المرونة) في الثعور بحالة السعادة والصحة، إلى ان هذه المتغيرات اسهمت في العناية بالذات واستراتيجيات إدارة الضغوط وامتد أثرها الى الثعور بالسعادة من المرؤوسين بالعمل.

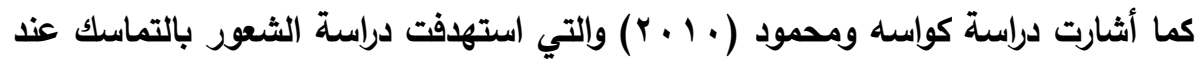
طلاب الجامعة وعلاقته بالصحة النفسية باستخدام مقياس انتونوفيسكى، إلى أنه يمكن التنبؤ

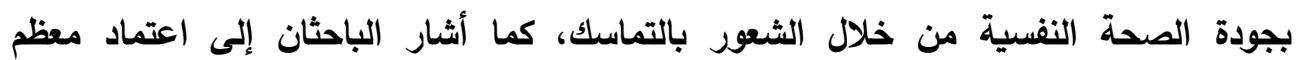
الاراسات على متغير الثعور بالسعادة لقياس الصحة النفسية.

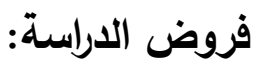

1. يوجد مستوى مرتفع من الثعور بالسعادة الذاتية وأبعادها لدى عينة الدراسة.

2. يوجد مستوى متوسط من الثعور بالتماسك وأبعاده لاى عينة الدراسة.

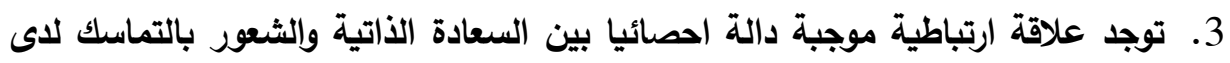

عينة الدراسة.

4. لا يوجد تأثير دال احصائيا لكل من المستوى الاراسي والتخصص والحالة الاجتماعية والتفاعلات الثنائية بينهما على السعادة الذاتية وأبعادها.

5. لا يوجد تأثير دال احصائيا لكل من المستوى الدراسي والتخصص والحالة الاجتماعية والتفاعلات الثنائية والثلاثية بينهم على الثعور بالتماسك وأبعاده. 6. لا يمكن التتبـؤ بالسعادة الذاتية من الثعور بالتماسك وأبعاده. حدود الاراسة: أ. الحدود الموضوعية: تتدد الدراسة بمتغيري (السعادة الاتية والثعور 
السعادة الأتية وعلاقتها بالثعور بالتماسك ------ د// هانم مصطفى محمد مصطفى البرعي

ب. الحدود المكانية: تم تطبيق الأدوات على عينة من طالبات جامعة الملك فيصل.

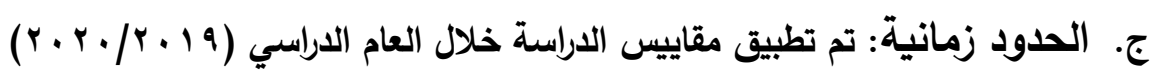
منهج الدراسة:

تم استخدام المنهج الوصفي الارتباطي والمقارن لدراسة العلاقات الارتباطية والفروق بين متغيرات الاراسة. اجراءات الدراسة:

أولا تقنين أدوات الدراسة باستخدام:

1. صدق المحكمين: لاختبار صدق البناء الداخلي لأدوات الدراسة.

2. التحليل العاملي التوكيدي: للتأكد من أبعاد المقياس وتثبع العوامل على أبعاد المقياس. 3. حساب معاملات الثبات بعدة طرق مثل (حساب معامل الفا كرو نباخ- معامل الثبات

(المركب).

ثانيا اختبار فروض الدراسة باستخدام الطرق الإحصائية الآتية: 1. اختبار تحليل التباين المتعدد: لدراسة الفروق في متوسطات درجات المتغيرات التابعة

في المتغيرات المستقلة المختلفة، ودراسة أثر المتغيرات المستقلة بالمتغيرات التابعة. 2. معامل ارتباط بيرسون: لحساب معاملات الارتباط.

3. الانحدار المتعدد: لاختبار التنبؤ لمتغيرات الدراسة. عينة الدراسة:

\section{العينة الاستطلاعية:}

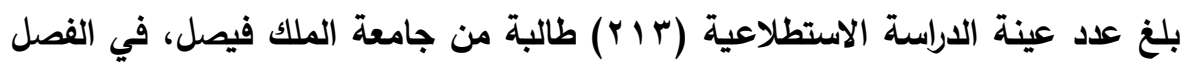

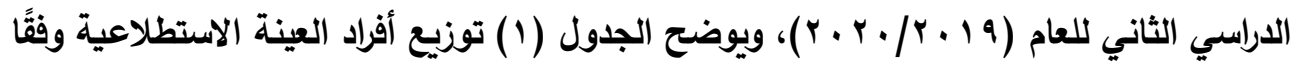

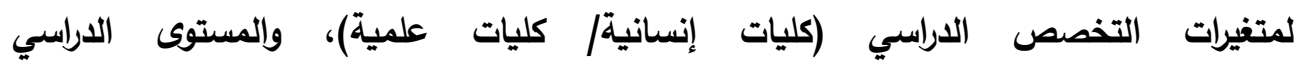
(الأول/الثاني/الثالث/(الرابع/الدراسات العليات)، والحالة الاجتماعية (أعزب/ متزوج).

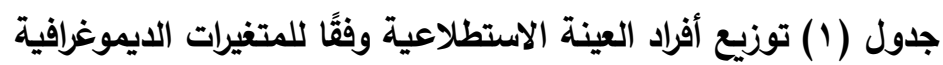

\begin{tabular}{|c|c|c|c|}
\hline النسبة المئوية & العدد & المتغير & المتغير \\
\hline 73.2 & 156 & العلمي & \multirow{3}{*}{ التخصص الاراسي } \\
\hline 26.8 & 57 & الإنساني & \\
\hline 100 & 213 & المجموع & \\
\hline 33.8 & 72 & الأول & المستوى الدراسي \\
\hline
\end{tabular}




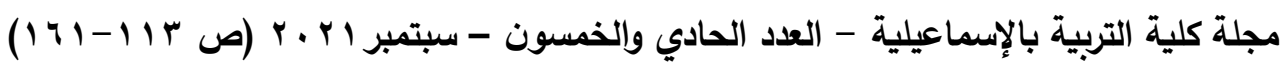

\begin{tabular}{|c|c|c|c|}
\hline 11.3 & 24 & الثاني & \\
\hline 15.5 & 33 & الثالث & \\
\hline 9.4 & 20 & الرابع & \\
\hline 30 & 64 & الدراسات العليا & \\
\hline 100 & 213 & المجموع & \\
\hline 72.3 & 154 & اعزب & \multirow{3}{*}{ الحالة الاجتماعية } \\
\hline 27.7 & 59 & متزوج & \\
\hline 100 & 213 & المجموع & \\
\hline
\end{tabular}

العينة الأسساسية:

بلغ عدد عينة الدراسة الاستطلاعية (r૧^) طالبة من جامعة الملك فيصل، في الفصل

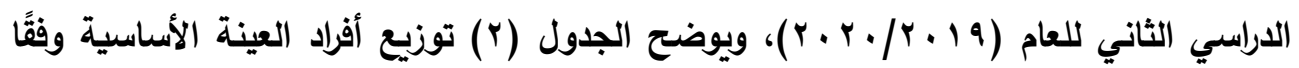
لمتغيرات التخصص الاراسي (كليات إنسانية/ كليات علمية)، والمستوى الدراسي (الأول/الثاني/الثالث/اليرابع/الاراسات العليات)، والحالة الاجتماعية (أعزب/ متزوج).

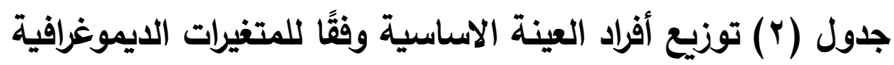

\begin{tabular}{|c|c|c|c|}
\hline النسبة المئوية & العدد & المتغير & المتغير \\
\hline 72.8 & 217 & العلمي & \multirow{3}{*}{ التخصص الدراسي } \\
\hline 27.2 & 81 & الإنساني & \\
\hline 100 & 298 & المجموع & \\
\hline 34.6 & 103 & الأول & \multirow{6}{*}{ المستوى الاراسي } \\
\hline 12.4 & 37 & الثاني & \\
\hline 15.8 & 47 & الثالث & \\
\hline 9.1 & 27 & الرابع & \\
\hline 28.2 & 84 & الاراسات العليا & \\
\hline 100 & 298 & المجموع & \\
\hline 70.8 & 211 & أعزب & \multirow{3}{*}{ الحالة الاجتماعية } \\
\hline 29.2 & 87 & متزوج & \\
\hline 100 & 298 & المجموع & \\
\hline
\end{tabular}

أدوات الدراسة:

أولا استبيان السعادة الذاتية لطلاب الجامعة: College Student Subjective

Wellbeing Questionnaire (CSSWQ)

اعد هذا الاستبيان رينشو و بولونينو (Renshaw \& Bolognino, 2014)، وتكون

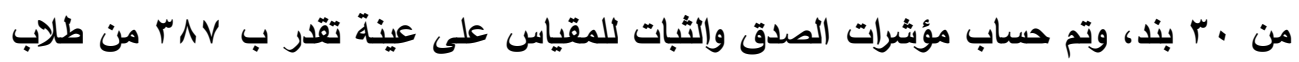
الجامعة، وأظهرت النتائج اتساقًا داخليًا قويًا، وارتباطا دال احصائيا مع العديد من المؤشرات العالمية للسعادة الذاتية، كما أظهرت النتائج ارتفاع معامل الفاكرونباخ للمقياس وابعاده الفرعية قرت ب • ^, •، وتكون الاستبيان من خمسة ابعاد هي ( الرضا الاكاديمي، المثابرة الاكاديمية، 
السعادة الأتية وعلاقتها بالشعور بالتماسك ------ د/ هانم مصطفى محمد مصطفى البرعي

الارتباط بالجامعة، كفاءة الذات الاكاديمية، الامتنان للكلية) تم التحقق منها بالتحليلي العاملي الاستكشافي والتوكيدي واظظهرت وجود عامل كامن واحد يضم العامل اربع ابعاد وهي (كفاءة الذات الاتيات

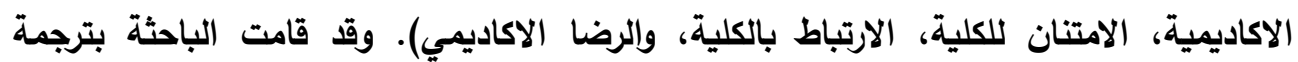
النسخة الأجنبية لاستبيان السعادة الذاتية، وتم عرضه على اثنين من المتخصصين في اللغة الإنجليزية لترجمته من العربية إلى الانجليزية، ووجد تطابقا بين الترجمتين مع الاستبيان

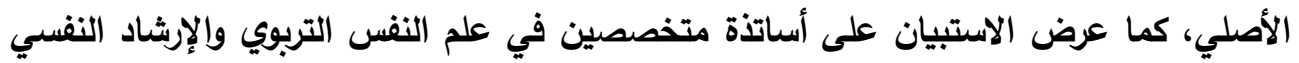
والصحة النفسية بكلية التربية بجامعة الملك فيصل لمراجعة الترجمة، وإبداء آرائهخ حول التماء الإئي بنود الاستبيان لما يقيسه ومناسبته للفئة العمرية لعينة الاراسة، بالإضافة لصحة الصياغة العلمية وإنتمائها لما وضعت لقياسه، وتم اعتماد نسبة الاتفاق ـ^\% بين المحكمين، وتم الابقاء على جميع بنود المقياس. وتكون الاستبيان من (·r) بند صيغت جميعها في الاتجاه الإيجابي، ويجاب عنها باختيار أحد البائل (اوافق بثدة -أوافق- محايد - غير موافق - غير موافق بافي

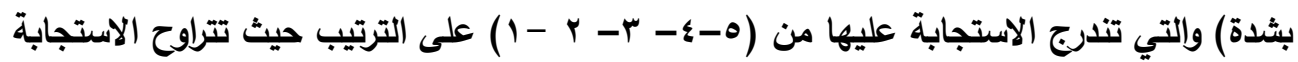

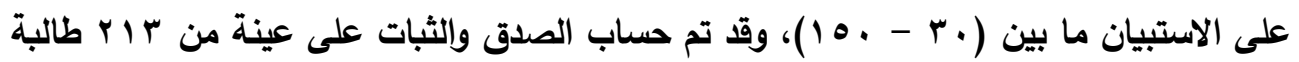
من جامعة الملك فيصل بالمملكة العربية السعودية تم اختيارهم بطريقة عشوائية لتقنين الاستبيان والتحقق من الخصائص السيكومترية كما يتضح فيما يلي: الخصائص السيكومترية:

\section{أ. صدق التكوين الفرضي: Construct Validity}

تم استخدام أسلوب التحليل العاملي التوكيدي (Confirmatory Factor Analysis) عن طريق برنامج اموس (Amos 21) للتحقق من صدق التكوين الفرضي لاستبيان السعادة الأتية، وتم الاعتماد على مؤشرات المطابقة الأكثر انتثارا واستخداما بين الباحثين في مجال النمذجة بالمعادلات البنائية، وذلك للتأكد من التطابق بين البنية النظرية الافتراضية والواقع المستمد من بيانات العينة، وقد تم حساب مؤشرات حسن المطابقة للتحقق من البنية العاملية للنموذج أحادي العامل وإعتماد نقطة قطع ء, . لتشبعات العامل المعيارية. (Stevens, 1992)

(Cited in: Saravia et al., 2015)

Modification تم تعديل النموذج لتحقيق المطابقة للنموذج باستخدام مؤشرات التعديل Indices

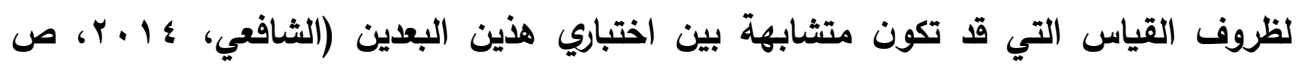




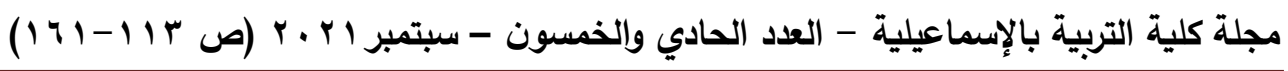

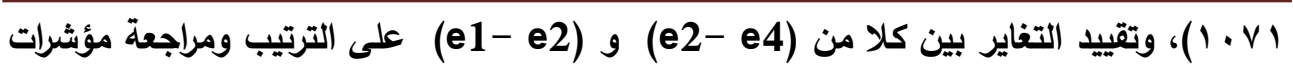
حسن المطابقة بعد كل تقييد، ويبين الثكل (1) نموذج مخطط المسار الافتراضي النهائي لاستبيان السعادة الذاتية، موضح فيه تشبعات العبارات (المتغيرات المشاهدة) بالعوامل الكامنة وإخطاء القياس الخاصة بالمتغيرات المشاهدة، كما يوضح جدول (؛) مؤشرات حسن المطابقة بنموذج العامل الواحد قبل وبعد التعديل.

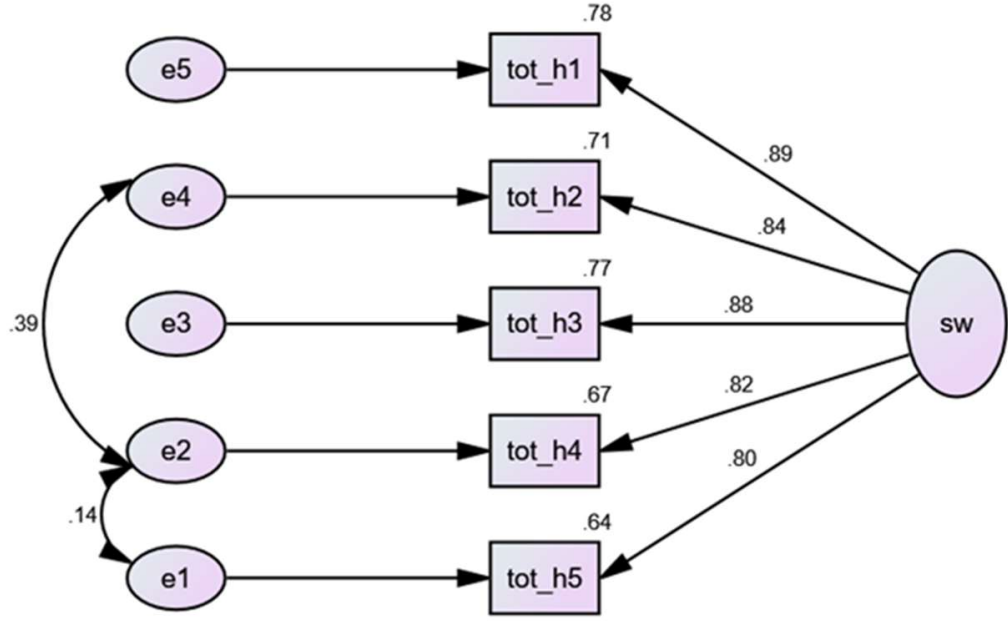

شكل (1) يوضح مخطط المسار الافتراضي لاستبيان السعادة الذاتية بتقديرات البارامترات

المعيارية

والجدول التالي يوضح تشبعات أبعاد استبيان السعادة الذاتية (معاملات الانحدار

المعيارية لبنود المقياس على العوامل الكامنة) ومستوياتها المعنوية، ومربعات معاملات الارتباط بين ابعاد الاستبيان والمتغير الكامن. جدول (r) معاملات الانحدار المعيارية للبنود (التثبعات) على العوامل الكامنة ومستوى

الالالة المعنوبية ومربعات معاملات الارتباط لاستبيان السعادة الذاتية

\begin{tabular}{|c|c|c|c|c|c|}
\hline مربع معاملات الارتباط & معامل الانحار المعياري (التشبع) & مستوى الالالة المعنوية & \multicolumn{3}{|c|}{ سارات بيان } \\
\hline 0.78 & .89 & دالة احصائيا & ot1 & --- & $\mathbf{W}$ \\
\hline 0.71 & .84 & دالة احصائيا & ot2 & -- & W \\
\hline 0.77 & .88 & دالة احصائيا & ot3 & -- & $\mathbf{W}$ \\
\hline 0.67 & .82 & ـالة احصائيا & & & \\
\hline
\end{tabular}


السعادة الذاتية وعلاقتها بالثعور بالتماسك ------ د/ هانم مصطفى محمد مصطفى البرعي

\begin{tabular}{|c|c|c|c|c|c|}
\hline بريع معاملات الارتباط & معامل الانحدار المعياري (التثبع) & مستوى الدلالة المعنوية & \multicolumn{3}{|c|}{ المسارات بيان } \\
\hline & & & ot4 & -- & $\mathbf{W}$ \\
\hline 0.64 & .80 & دالة احصائيا & ot5 & --. & $\mathbf{W}$ \\
\hline
\end{tabular}

يتضح من نتائج جدول (ب) ما يلي:

أن جميع أوزان الانحدار المعيارية (التشبعات) للمتغير الكامن (SW) على ابعاد استبيان

السعادة الذاتية (tot1-tot2-tot3-tot4-tot5) كانت دالة احصائيا، وتراوحت تشبعات الأبعاد بين (0.89-0.89) وهي قيم مرتفعة لتشبعات الأبعاد بالعامل الكامن، وجميعها دالة

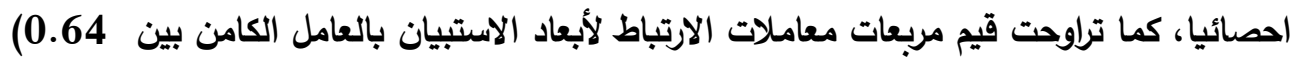
(0.78) - وهي قيم مرتفعة لتفسير التباين في المتغير الكامن بواسطة ابعاد الاستبيان.

وللتحقق من حسن مطابقة نموذج العامل العام للبيانات Model Fit Summary: تم

حساب مؤشرات حسن المطابقة للنموذج والجدول التالي يوضح ذلك. جدول (ء) مؤشرات حسن مطابقة نموذج العامل العام لاستبيان السعادة الذاتية قبل وبعد

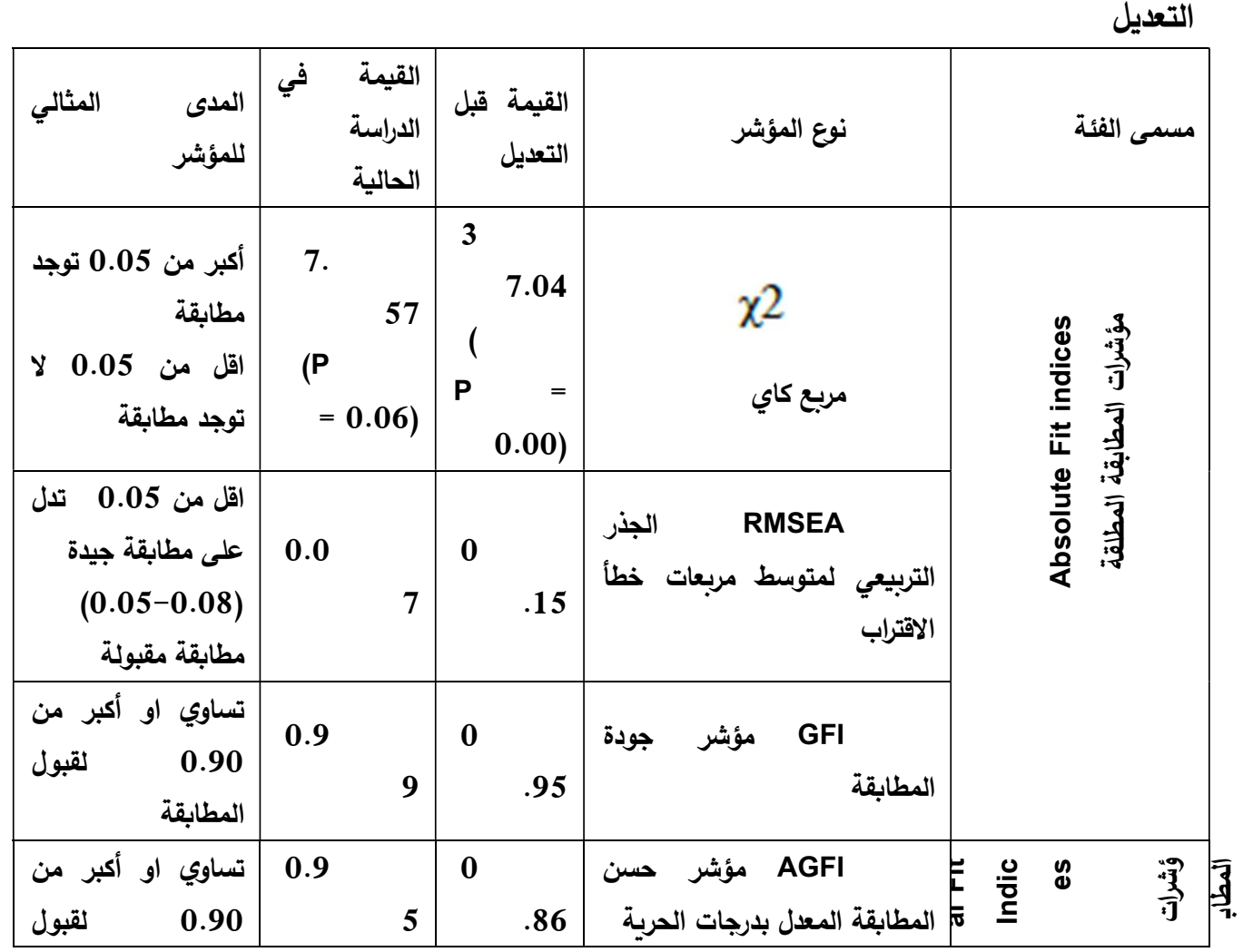




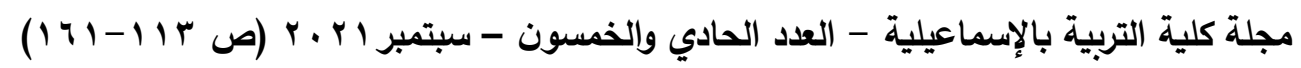

\begin{tabular}{|c|c|c|c|c|}
\hline \multirow[t]{3}{*}{ المطابقة } & 0.9 & $\begin{array}{ll}0 & \\
& .97 \\
\end{array}$ & المقارن $\quad$ CFI مؤشر المطابقة & \\
\hline & 0.9 & $\begin{array}{ll}0 & \\
& .95\end{array}$ & مؤشر توكر -لويس TLI & \\
\hline & 0.9 & $\begin{array}{ll}0 & \\
& .97\end{array}$ & المعياري NFI مؤشر الملائمة & \\
\hline اقل من القيمة هـ & 2.5 & $\begin{array}{ll}7 & \\
& .41\end{array}$ & $\begin{array}{l}\text { تعارض الى درجة الحرية ق CMIN DF } \\
\text { قيمة اقل }\end{array}$ & $\begin{array}{l}\text { Parsmoni } \\
\text { ous Fit Indices } \\
\text { لمؤشرات الاقتصادية }\end{array}$ \\
\hline
\end{tabular}

يتضح من مراجعة جدول (؛) لقيم مؤشرات جودة المطابقة لنموذج البيانات ان غالبية

Modification المؤشرات جاءت مطابقة لمحكات جودة المطابقة باستخدام مؤشرات التعديل

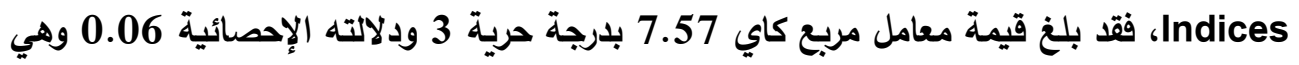
غير دالة احصائيا ويشير ذلك الى عدم وجود فروق جوهرية بين النموذج المفترض وبيانات

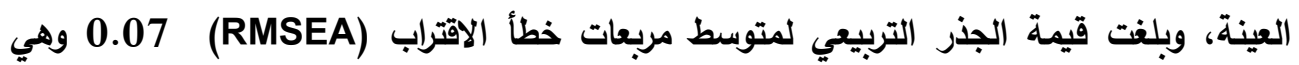

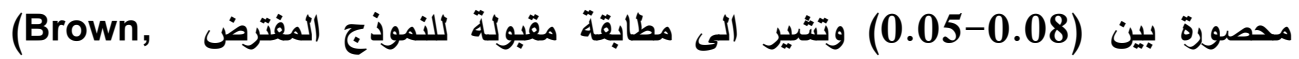
(2015. كما بلغت قيمة مؤشر حسن المطابقة (GFI) 0.99 ، ومؤشر حسن المطابقة المعدل

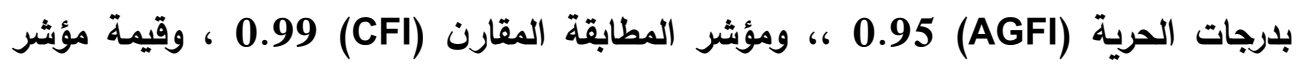
توكي - لويس 0.99 (TLI) وجميعها قيم قريبة من 1 ، ويشير ذلك الى ملائمة مقبولة

$$
\text { لنموذج البيانات . }
$$

يتضح مما سبق حسن مطابقة النموذج للبيانات، وبهذا قدم التحليل العاملي التوكيدي دليلا على صدق لاستبيان السعادة الذاتية لطلاب الجامعة في البيئة السعودية. ب. صدق المحك:

تم حساب قيم معاملات ألفا كرونباخ والمتوسط والتباين معامل الارتباط المصحح بعد حذف البند من الاستبيان لتقييم صلاحية البنود هو في الوقت نفسه أحد أنواع صدق المحك

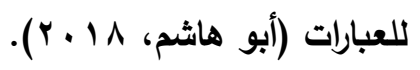


السعادة الأتية وعلاقتها بالثعور بالتماسك ------ د/ هانم مصطفى محمد مصطفى البرعي

جدول (0) المتوسطات والتباين ومعامل الارتباط المصحح ومعامل ألفا كرونباخ بعد حذف

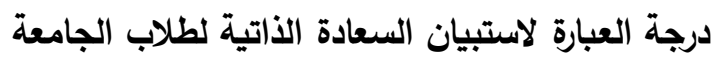

\begin{tabular}{|c|c|c|c|c|c|}
\hline معامل الفا كرونباخ & الارتباط المصحح & التباين & المتوسط & قُم العبارة & البعد | البد \\
\hline .962 & .655 & 420.195 & 113.896 & 1. & \multirow{6}{*}{$\overline{3}$} \\
\hline .963 & .550 & 419.196 & 113.658 & 2. & \\
\hline .961 & .733 & 416.567 & 113.584 & 3. & \\
\hline .962 & .674 & 419.747 & 113.611 & 4. & \\
\hline .961 & .712 & 415.938 & 113.752 & 5. & \\
\hline .963 & .562 & 418.337 & 113.987 & 6. & \\
\hline .962 & .659 & 414.733 & 113.966 & 7. & \multirow{6}{*}{ 柔 } \\
\hline .963 & .560 & 420.458 & 113.859 & 8. & \\
\hline .962 & .654 & 418.405 & 113.849 & 9. & \\
\hline .961 & .731 & 416.282 & 113.628 & 10. & \\
\hline .962 & .594 & $\mathbf{4 2 0 . 5 3 7}$ & 113.738 & 11. & \\
\hline .962 & .673 & 420.354 & 113.396 & 12. & \\
\hline .961 & .722 & 414.726 & 113.822 & 13. & \multirow{6}{*}{ 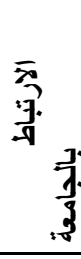 } \\
\hline .961 & .708 & 412.933 & 113.946 & 14. & \\
\hline .962 & .685 & 417.284 & 113.674 & 15. & \\
\hline .961 & .727 & 414.129 & 113.701 & 16. & \\
\hline .961 & .710 & 415.756 & $\mathbf{1 1 3 . 5 9 7}$ & 17. & \\
\hline .962 & .630 & 422.903 & 113.409 & 18. & \\
\hline .962 & .626 & 422.713 & 113.547 & 19. & \multirow{6}{*}{ 哥哥 } \\
\hline .962 & .648 & 418.050 & 113.805 & 20. & \\
\hline .962 & .674 & 420.625 & 113.651 & 21. & \\
\hline .961 & .733 & 418.708 & 113.530 & 22. & \\
\hline .961 & .730 & 419.599 & 113.430 & 23 & \\
\hline .961 & .726 & 418.397 & 113.721 & 24. & \\
\hline .961 & .705 & 421.840 & 113.242 & 25. & \multirow{6}{*}{ 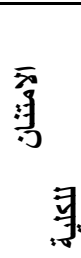 } \\
\hline .961 & .727 & 414.509 & 113.742 & 26. & \\
\hline .961 & .741 & 420.662 & 113.386 & 27. & \\
\hline .962 & .656 & 423.546 & 113.245 & 28. & \\
\hline .962 & .670 & 421.197 & 113.309 & 29. & \\
\hline .962 & .621 & 424.943 & 113.181 & 30. & \\
\hline
\end{tabular}

يتضح من جدول (0) ما يلي:

- ان المدى الذي تتذبذب فيه قيم المتوسطات (113.99 - 113.18)،

والتباين (424.94 - 412.93) وهو مدى صغير، يثير الى ان جميع العبارات

متجانسة الى حد كبير في قياس ما وضعت لقياسه.

- جميع معاملات الارتباط المصحح بين العبارات والدرجة الكلية للمقياس عند

حذف درجة العبارة دالة احصائيا وتراوحت بين (74. - 55.). 


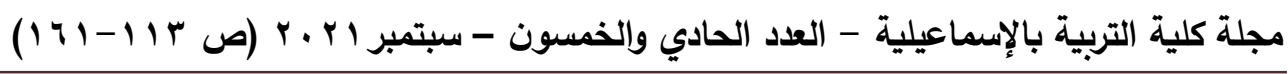

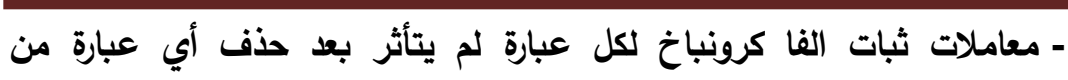

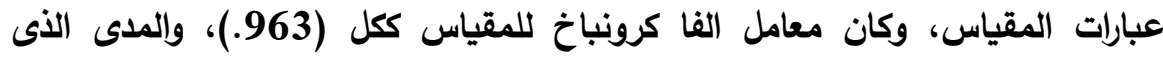

يتذبذب فيه معامل الفا كرونباخ صغير تراوح بين (963. - 961. كل بند في الاستبيان يسهح بثكل مناسب في معامل ثبات الارجة الكلية لاستبيان

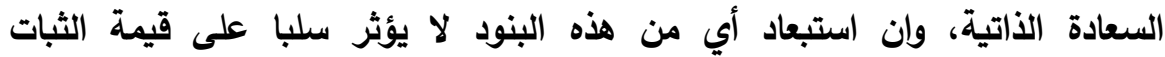

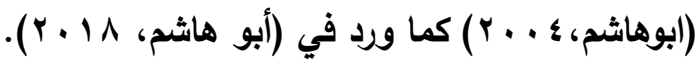

$$
\begin{aligned}
& \text { ب. حساب الاتساق الداخلي: }
\end{aligned}
$$

تم حساب الاتساق الداخلي لعبارات استبيان السعادة الذاتية، وذلك بإيجاد قيم

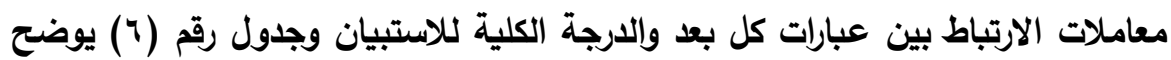

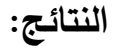

جدول (†) معاملات الارتباط بين العبارات والارجة الكلية لاستبيان السعادة الذاتية

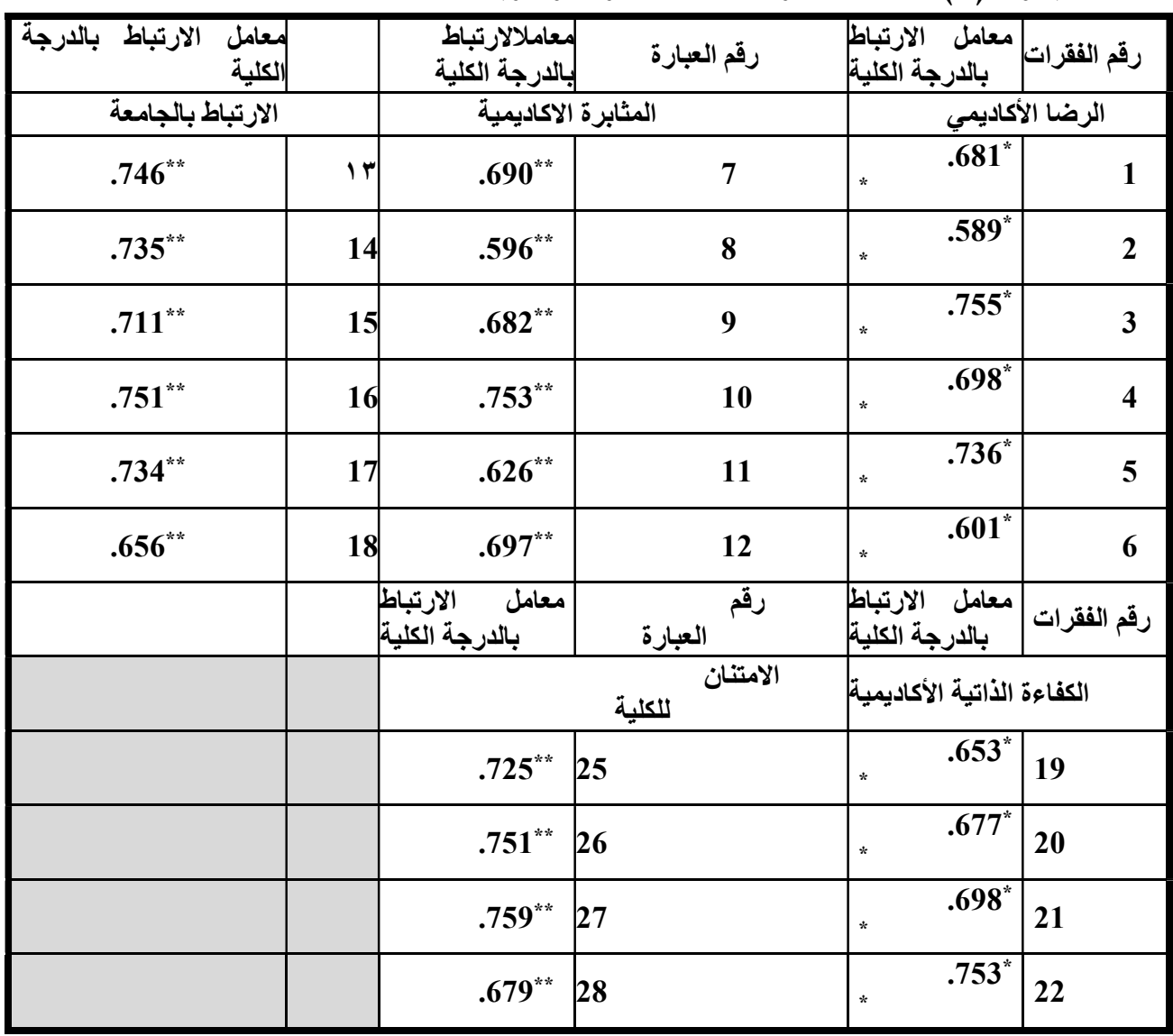


السعادة الاتية وعلاقتها بالثعور بالتماسك ------ د/ هانم مصطفى محمد مصطفى البرعي

\begin{tabular}{|c|c|c|c|c|c|}
\hline & & $.693^{* * *}$ & 29 & $.750^{*}$ & 23 \\
\hline & & $.646^{* * *}$ & 30 & $.747^{*}$ & 2 \\
\hline
\end{tabular}

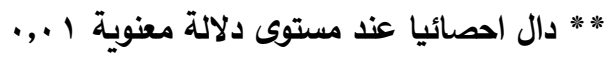

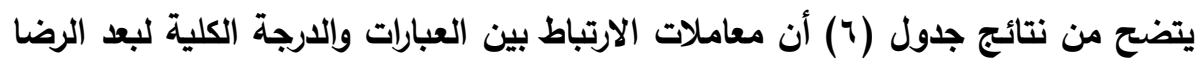

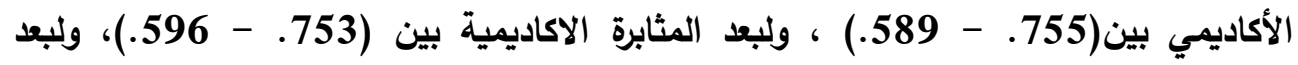

الارتباط بالجامعة بين (746. - 656.)، ولبعد الكفاءة الذاتية الاكاديمية بين - 653.

(753.، وبعد الامتنان للكلية بين (759. - 646.)، وجميع معاملات الارتباط بين عبارات

استبيان السعادة الأتية واللارجة الكلية كانت دالة احصائيا عند مستوى دلالة معنوية (0.01).

ووفق هذه النتائج يظل عدد العبارات . r عبارة لاستبيان السعادة الذاتية لطلاب الجامعة.

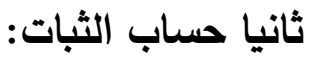

تم حساب معاملات الفا كرونباخ لأبعاد الاستبيان والاستبيان ككل ومعامل الثبات

المركب(CR) لاستبيان السعادة الذاتية وجدول (V) يوضح نتائج ذلك:

جدول (V) معاملات ألفا كرونباخ لأبعاد استبيان السعادة الذاتية لطلاب الجامعة

\begin{tabular}{|c|c|c|}
\hline الثبات المركب0.06 المب & معامل الفا كرونباخ & الابعاد \\
\hline \multirow{6}{*}{1.17} & .841 & البعد الأول (الرضا الأكاديمي) \\
\hline & .845 & البعد الثاني (المثابرة الاكاديمية) \\
\hline & .895 & البعد الثالث (الارتباط بالجامعة) \\
\hline & .887 & البعد الرابع (الكفاءة الذاتية الاكاديمية) \\
\hline & .911 & البعد الخامس (الامتنان للكلية \\
\hline & .963 & الاستبيان ككل \\
\hline
\end{tabular}

يتضح من نتائج جدول (V) ما يلي: الفي كرون

- ان معاملات الفا كرونباخ للثبات جاءت بقيم مرتفعة وتراوحت للأبعاد بين

(911. - 841. ولنلاستبيان ككل 963.

- ان قيمة معامل الثبات المركب (CR) للبناء الكامل للاستبيان كانت مساوية

(1.17) اي اكبر من اقل قيمة دالة القيمة 06.، ما يشير الى تمتع النموذج بثبات

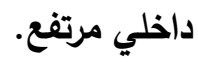

يتضح مما سبق أن استبيان السعادة الذاتية يتمتع بمعاملات صدق وثبات

مقبولة مما يثير إلى صلاحيته للتطبيق على العينة الأساسية. 


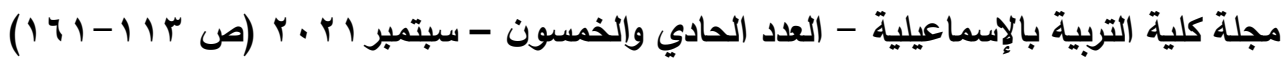

ثانيا مقياس الشعور بالتماسك: Sense Of Coherence scale (SOC) أعد هذا المقياس انتونفيسكسي (Antonovsky, 1987) وتكون من ه ؛ عبارة في نسخته

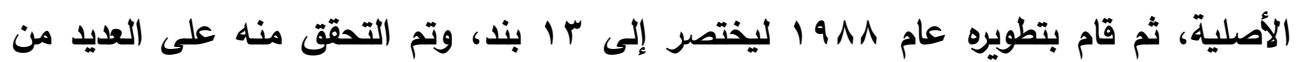

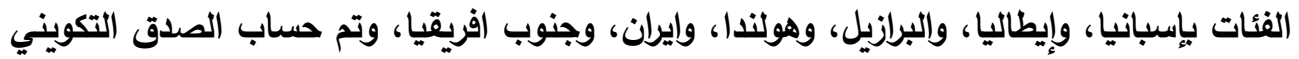

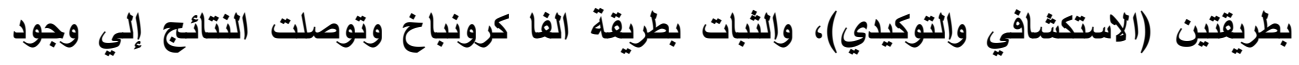
مستوى مقبول للثبات يتراوح من 0.59 الى0.70.، ووجود ثلاث عوامل للمقياس ذات مستوى

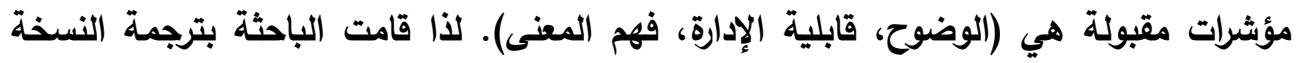

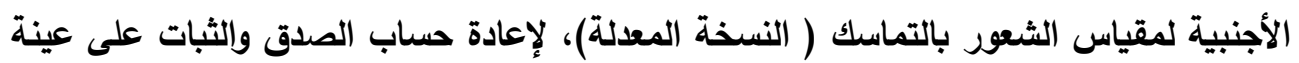

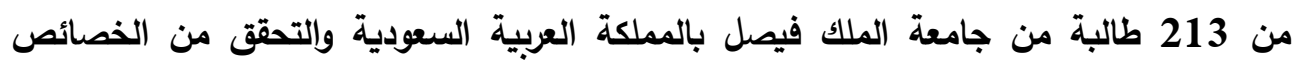

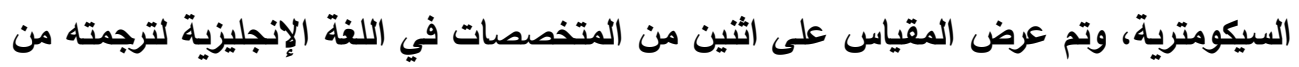

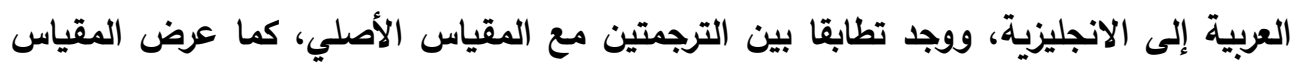

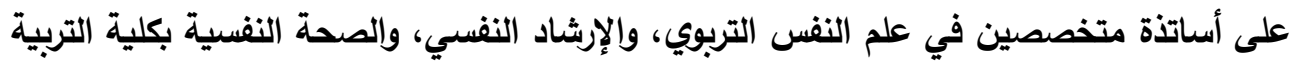
بجامعة الملك فيصل لمراجعة الترجمة، وإبداء آرائهم حول انتماء بنود المقياس لمادئ لما تقيسه

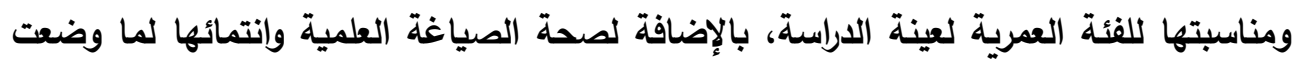

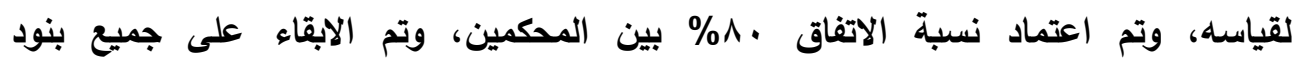

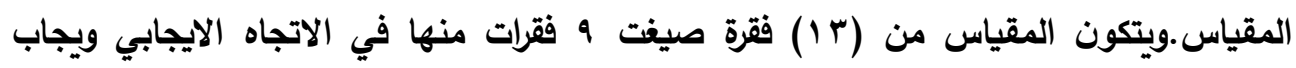

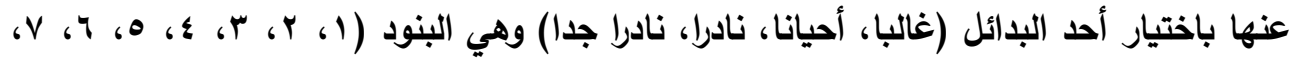

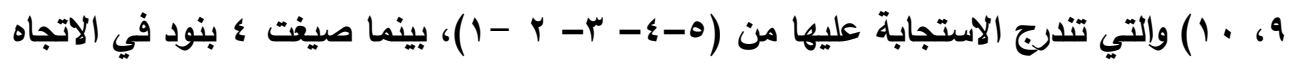

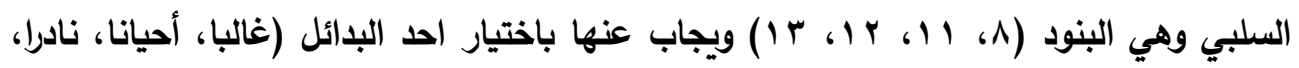

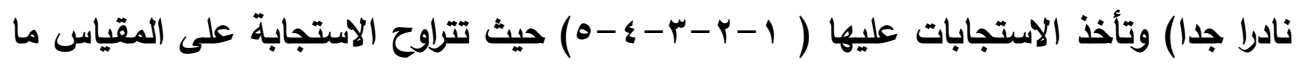

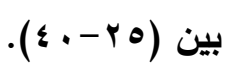

الخصائص السيكومترية للمقياس:

أ. صدق التكوين الفرضي: Construct Validity

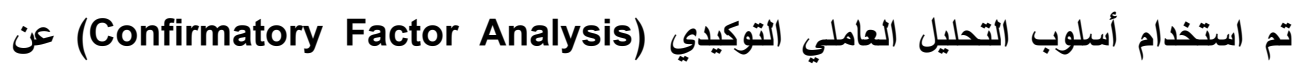
طريق برنامج أموس (Amos 21) للتحقق من صدق التكوين الفرضي لمقياس التماسك، وتم

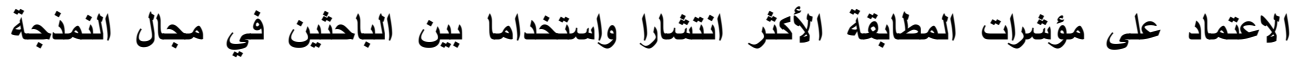

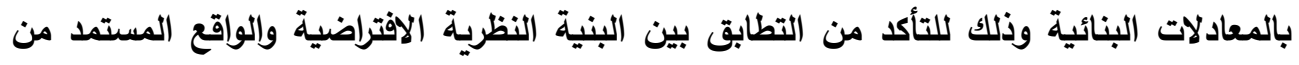


السعادة الأتية وعلاقتها بالثعور بالتماسك ------ د/ هانم مصطفى محمد مصطفى البرعي

بيانات العينة، وقد تم حساب مؤشرات حسن المطابقة للتحقق من البنية العاملية للنموذج أحادي

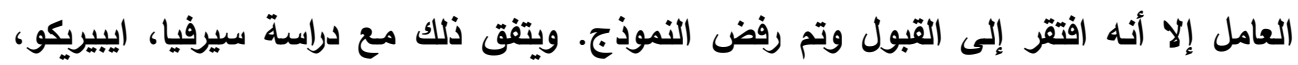
وييروود (Saravia, Iberico \& Yearwood, 2015) والتي اختبرت نموذج مقياس

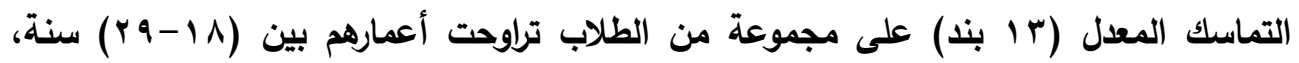
وأثارت نتائج التحقق من الخصائص السيكومترية للمقياس الى تمتع المقياس بمؤشرات للثبات مقبولة تراوحت من (9ه، - 11،) لأبعاد المقياس الثلاث، وبمؤشرات صدق تكويني مقبولة لنموذج العوامل الثلاث للتحليل العاملي التوكيدي.

ولحساب الصدق التكويني لنموذج العوامل الثلاث لمقياس التماسك الحالي تم اعتماد نقطة قطع ع ، لتشبعات العامل المعيارية (Ctevens, 1992) (Cited in: Saravia et al., 2015)، وتم حذف البند (· (1) بعد اجراء التحليل التوكيدي ببرنامج (Amos 20) حيث أن تشبع الفقرة

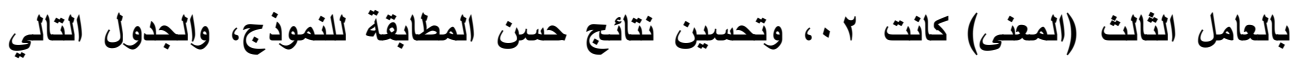
يوضح نتائج التحليل التوكيدي قبل وبعد حذف البند، والثكل (ץ) يبين نموذج مخطط المسار

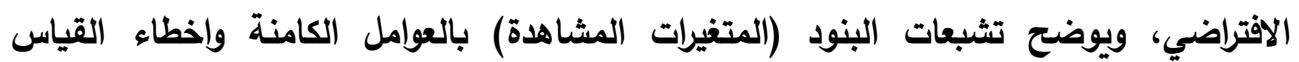
الخاصة بالمتغيرات المشاهدة.

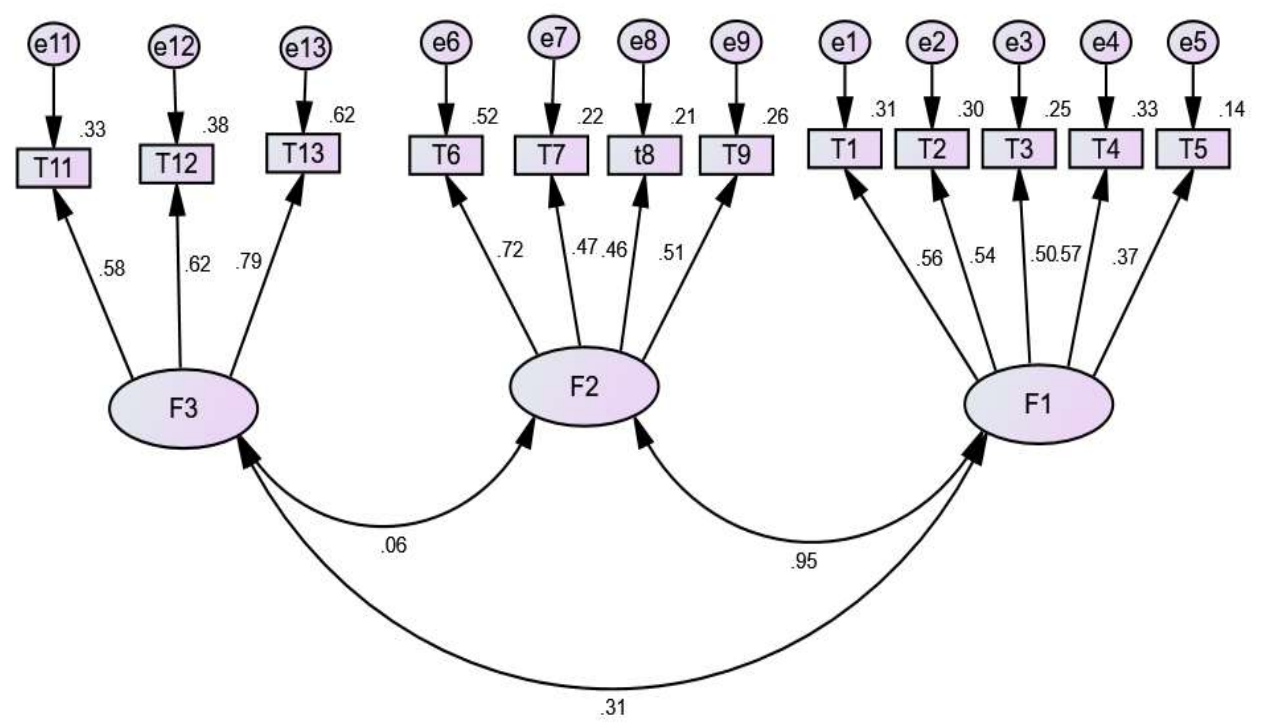

شكل (r) يوضح مخطط المسار الافتراضي لمقياس الشعور بالتماسك بتقديرات البارامترات المعيارية 


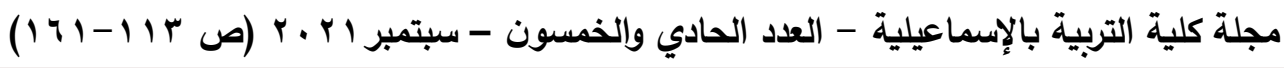
يوضح الثكل السابق نموذج المسار الافتراضي لمقياس الثعور بالتماسك بالتقديرات المعيارية، ويتضح فيه معاملات تشبعات البنود على العوامل الثلاث الكامنة ومربعات معاملات

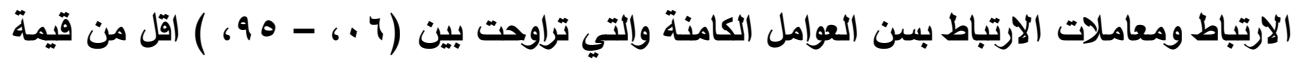

وجدول رقم (^) يوضح تشبعات بنود مقياس الثعور بالتماسك (معاملات الانحدار

المعيارية لبنود المقياس على العوامل الكامنة) ومستوياتها المعنوية بعد حذف البند ( • (1). جدول (^) معاملات الانحدار المعيارية للبنود (التثبعات) على العوامل الكامنة ومستوى الدلالة المعنوية لمقياس الثعور بالتماسك

\begin{tabular}{|c|c|c|c|c|c|}
\hline مربع الارتباط معاملات & (المعياري ب الانحدار & المعنوية الالالة & & \multicolumn{2}{|c|}{ بيان المسارات } \\
\hline 0.31 & $\cdot .56$ & دالة احصائيا & T1 & $<--$ & F1 \\
\hline 0.30 & $\cdot .54$ & دالة احصائيا & T2 & $<---$ & F1 \\
\hline 0.25 & $\cdot .50$ & دالة احصائيا & T3 & $<---$ & F1 \\
\hline 0.33 & $\cdot .57$ & |دالة احصائيا & T4 & $<--$ & F1 \\
\hline 0.12 & 0.37 & دالة احصائيا & T5 & $<---$ & F1 \\
\hline 0.53 & 0.72 & دالة احصائيا & T6 & $<---$ & F2 \\
\hline 0.22 & 0.47 & دالة احصائيا & T7 & $<---$ & F2 \\
\hline 0.21 & 0.46 & دالة احصائيا & T8 & $<--$ & F2 \\
\hline 0.26 & 0.51 & دالة احصائيا & T9 & $<---$ & F2 \\
\hline 0.33 & 0.58 & دالة احصائيا & T11 & $<---$ & F3 \\
\hline 0.38 & 0.62 & دالة احصائيا & T12 & $<---$ & F3 \\
\hline 0.62 & 0.79 & |دالة احصائيا & T13 & $<---$ & F3 \\
\hline
\end{tabular}

يتضح من نتائج جدول (^) ما يلي:

- أن جميع أوزان الانحدار المعيارية للمتغيرات الكامنة على المتغيرات المشاهدة

(التشبعات) كانت دالة احصائيا وتراوحت تشبعات باقي البنود بين 0.4 - 0.8 )

وجميعها دالة احصائيا.

- وفيما يخص البعد الأول (الوضوح) فان اكثر البنود اشباعا لهذا البعد(F1)

كان البند (T4) هل حدث انك شعرت بعدم قدرتك على التحمل؟، حيث بلغ قيمة تشبع العامل المعيارية 0.57 ، بينما كان اقلها اشباعا الفقرة (T5) حينما تقع أحداث معينة تجد نفسك قد قمت بتقييم الوضع بثكل صحيح، حيث بلغ قيمة تشبع العامل المعيارية 0.37 الا انها تقترب من قيمة القطع 0.4 لذا تم الإبقاء عليها. 
السعادة الأتية وعلاقتها بالثعور بالتماسك ------ د/ هانم مصطفى محمد مصطفى البرعي

- وبالنسبة للعامل الثاني(قابلية الإدارة) فان اكثر البنود اشباعا لهذا البعد(F2)

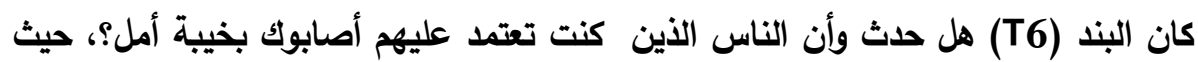

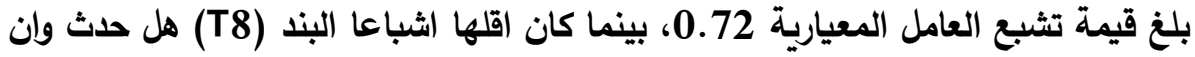

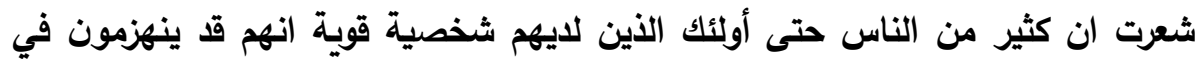
مواقف الحياة، حيث بلغ قيمة تثبع العامل المعيارية 0.47

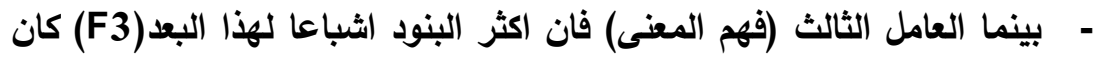
البند (T13) لاي شعور بأن هناك حكمة وراء الأثشياء التي أقوم بها في حياتي اليومية، حيث بلغ قيمة تثبع العامل المعيارية 0.79 ، بينما كان اقلها اشباعا كان البند (11)

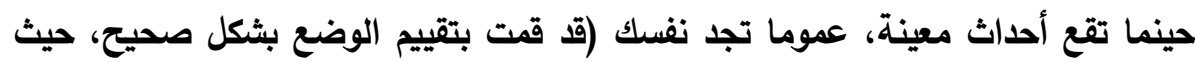
بلغ قيمة تثبع العامل المعيارية 0.58 . - ما يبين الجدول السابق تقديرات مربعات معاملات الارتباط بين المتغيرات

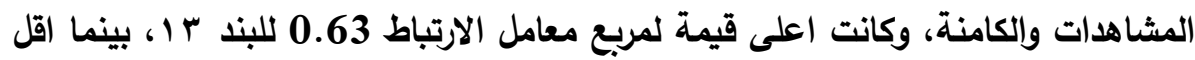
مربع معامل ارتباط 0.12 للبند ه، وهي نسبة التباين المفسر للمتغيرات المثاهدة والتي

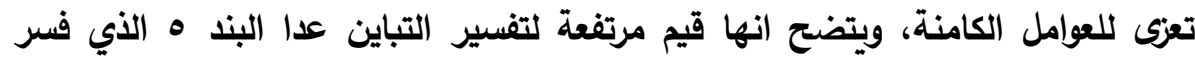

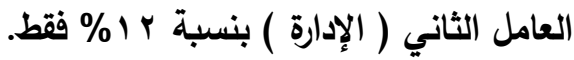

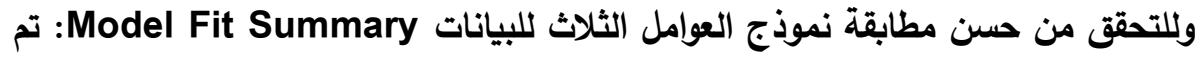
حساب مؤشرات حسن المطابقة للنموذج والجدول رقم (9) يوضح ذلك الكان. جدول (9) مؤشرات حسن مطابقة نموذج العوامل الثلاث لمقياس الثعور بالتماسك

\begin{tabular}{|c|c|c|c|c|}
\hline & & & & قبل وبعد التعديل \\
\hline المدى المثالي للمؤشر & القاليمة في الاراسة & القيمة قبل التعديل & المؤشر نوع & مسمى الفئة \\
\hline 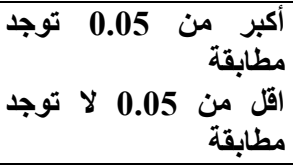 & $\left(P^{78.01}=\right.$ & $\left(\begin{array}{l}126.02 \\
=\end{array}\right.$ & $\begin{array}{l}x 2 \\
\text { مربع كاي }\end{array}$ & 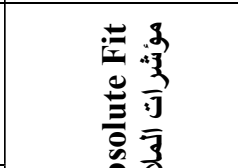 \\
\hline 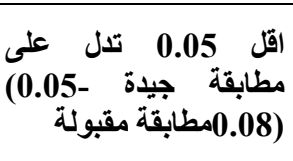 & 0.04 & 0.06 & 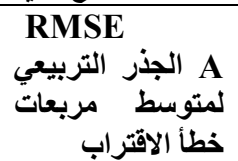 & 言 \\
\hline تقبول المطابقة او أكبر من 0.90 & 0.96 & 0.94 & مؤشر & \\
\hline تساوي او أكبر من & 0.93 & 0.91 & AGFI & $9 \cdot 37-10$ \\
\hline
\end{tabular}




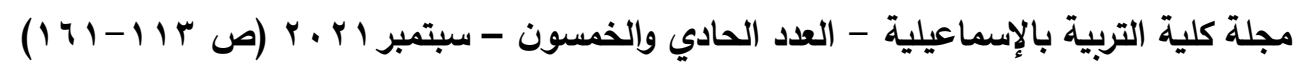

\begin{tabular}{|c|c|c|c|c|}
\hline \multirow[t]{4}{*}{0.90 لقبول المطابقة } & & & 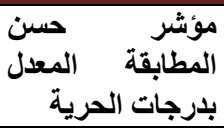 & \\
\hline & 0.96 & 0.90 & $\begin{array}{cc}\text { CFI } & \\
\text { المؤشرن } & \\
& \text { المطابقة } \\
\end{array}$ & \\
\hline & 0.94 & 0.87 & $\begin{array}{c}\text { TLI } \\
\text { مؤشر توكر-لويس }\end{array}$ & \\
\hline & 0.86 & 0.83 & مؤشر $\quad$ NFI الملائمة & \\
\hline اقل من القيمة ه & 1.53 & 2.05 & 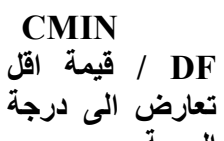 & $\begin{array}{r}\text { Parsimonious } \\
\text { Fit }\end{array}$ \\
\hline
\end{tabular}

يتضح من مراجعة جدول (9) لقيم مؤشرات جودة المطابقة لنموذج البيانات ان غالبية

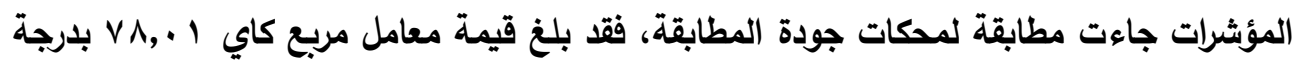

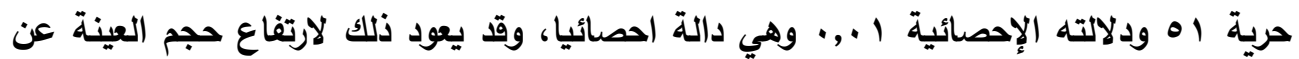

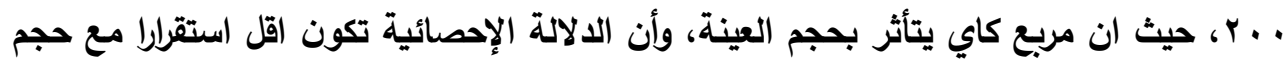

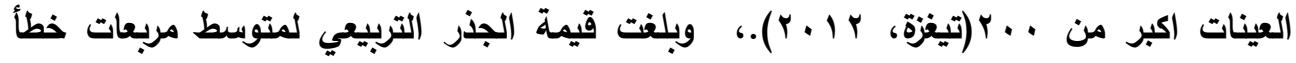

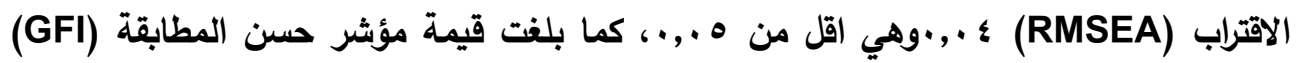

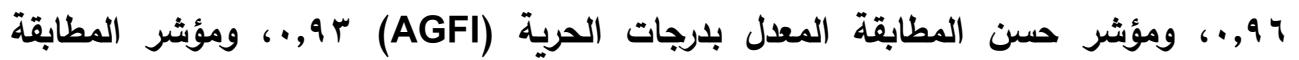

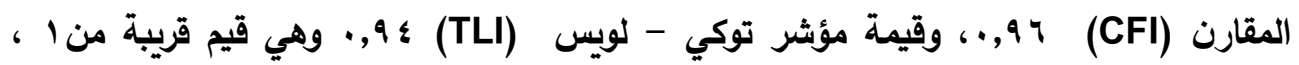
ويشير ذلك الى مطابقة نموذج البيانات الحالي، يتضح مما سبق حسن مطابقة النموذج للبيانات، وبهذا قدم التحليل العاملي التوكيدي دليلا على صدق مقياس الشعور بالتماسك في البيئة السعودية. ب. صدق المحك: تم حساب قيم معاملات الفا كرونباخ والمتوسط والتباين معامل الارتباط المصحح بعد حذف البند من المقياس لتقييم صلاحية البنود هو في الوقت نفسه أحد أنواع صدق المحك

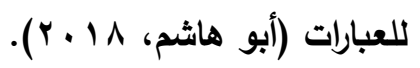


السعادة الأتية وعلاقتها بالثعور بالتماسك ------ د/ هانم مصطفى محمد مصطفى البرعي

جدول ( • (1) المتوسطات والتباين ومعامل الارتباط المصحح ومعامل ألفا بعد حذف درجة

الفقرة لمقياس الثعور بالتماسك

\begin{tabular}{|c|c|c|c|c|c|}
\hline معامل ألفا & معامل الارتباط & التباين & المتوسط & الفقرات & البعد \\
\hline .719 & .44 & 26.36 & 28.27 & 1 & \multirow{5}{*}{ الوضوح } \\
\hline .717 & .45 & 25.93 & 27.67 & 2 & \\
\hline .717 & .45 & 25.11 & 28.09 & 3 & \\
\hline .714 & .48 & 25.46 & 28.11 & 4 & \\
\hline .733 & .33 & 25.99 & 27.32 & 5 & \\
\hline .708 & .52 & 24.84 & 27.93 & 6 & \multirow{4}{*}{ قالإبلية } \\
\hline .722 & .41 & 25.25 & 27.70 & 7 & \\
\hline .735 & .30 & 26.81 & 27.92 & 8 & \\
\hline .726 & .38 & 26.16 & 27.98 & 9 & \\
\hline .739 & .26 & 27.70 & 26.70 & 11 & \multirow{3}{*}{ فهنج } \\
\hline .741 & .25 & 27.47 & 26.97 & 12 & \\
\hline .739 & .27 & 27.43 & 26.79 & 13 & \\
\hline
\end{tabular}

يتضح من جدول (· (1) ما يلي:

- ان المدى الذى تتذبذب فيه قيم المتوسطات (28.27-26.79) والتباين

(25.11-27.70) وهو مدى صغير، يثير الى ان جميع العبارات متجانسة الى حد

$$
\text { كبير في قياس ما وضعت لقياسه. }
$$

- جميع معاملات الارتباط المصحح بين البنود للمقياس والدرجة الكلية للمقياس

$$
\text { عند حذف درجة البند دالة احصائيا وتراوحت بين (52.-25.). }
$$

- معاملات ثبات الفا كرونباخ لكل بند لم يتأثر بعد حذف أي بند من بنود

المقياس، وكان معامل الفا كرونباخ للمقياس ككل (743.)، والمدى الذى يتذبذب فيه

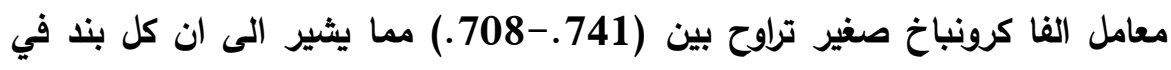
المقياس يسهم بثكل مناسب في معامل ثبات الارجة الكلية لمقياس التماسك، وان استبعاد أي من هذه البنود لا يؤثر سلبا على قيمة الثبات (ابوهاشم، ع . . ب) كما ورد

$$
\begin{aligned}
& \text { في (أبو هاشم، } 11 \text { ـ ب). } \\
& \text { ج. حساب الاتساق الداخلي: }
\end{aligned}
$$

تم حساب الاتساق الأخلي لعبارات مقياس الثعور بالتماسك، وذلك بإيجاد قيم معاملات الارتباط بين عبارات كل بعد والدرجة الكلية للمقياس وجدول (1 1 ) يوضح النتائج: 


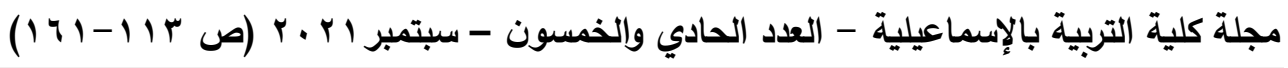
جدول (1 1 ) معاملات الارتباط بين العبارات والدرجة الكلية لمقياس الثعور

بالتماسك

\begin{tabular}{|c|c|c|c|c|c|c|}
\hline الالكلية & الارتباط & رقم العبارة & الارتباط معامل بالدرجة & رقم العبارة & 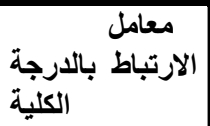 & رقم \\
\hline \multicolumn{3}{|c|}{ فهم المعنى } & \multicolumn{2}{|l|}{ قابلية الإدارة } & \multicolumn{2}{|l|}{ الوضوح } \\
\hline & $.411^{* *}$ & 1 & $.583^{* *}$ & 6 & $.527^{* *}$ & 1 \\
\hline & $.414^{* *}$ & 2 & $.553^{* *}$ & 7 & $.521^{* *}$ & 2 \\
\hline \multirow{3}{*}{\multicolumn{2}{|c|}{$.453^{* *}$}} & 3 & $.169^{* *}$ & 8 & $.574^{* *}$ & 3 \\
\hline & & & $.465^{* *}$ & 9 & $.591^{* *}$ & 4 \\
\hline & & & & & $.519^{* *}$ & 5 \\
\hline
\end{tabular}

يتضح من نتائج جدول (1 1) أن جميع معاملات ارتباط البنود مع الارجة الكلية لمقياس

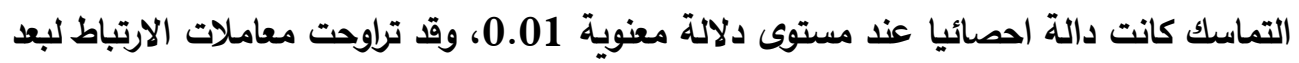
الوضوح بين (591. - 519.)، ولبعد قابلية الإدارة بين (583. - 169.)، ولبعد فهم المعنى $(.411-.453)$ ووفق هذه النتائج يظل عدد الفقرات با لمقياس التماسك (الصورة المختصرة) كما اشارت اليه نتائج دراسة (Saravia et al., 2015) ثانيا حساب الثبات:

تم حساب معاملات الفا كرونباخ، ومعاملات الثبات المركب Composite Reliability (CR) جدول (r I ) معاملات الفا كرونباخ لأبعاد مقياس الثعور بالتماسك والمقياس ككل

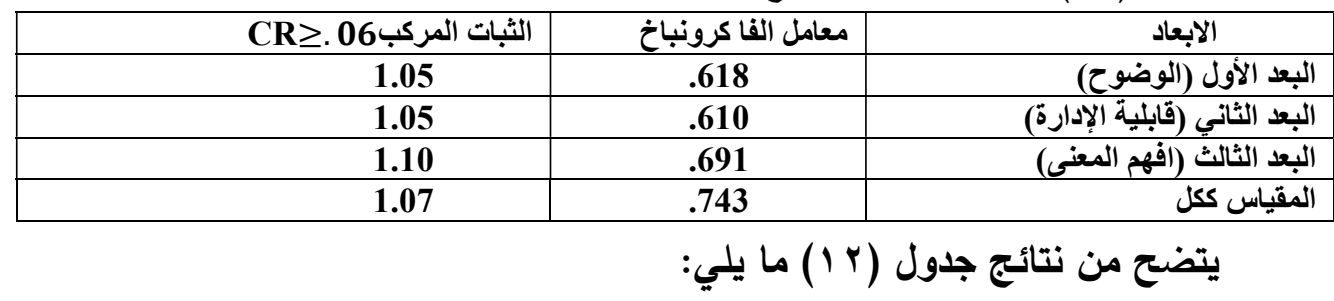

- ان معاملات الفا كرونباخ للثبات جاءت بقيم مقبولة وتراوحت للأبعاد بين -610.)

(691) (بلمقياس ككل 743. 
السعادة الأتية وعلاقتها بالثعور بالتماسك ------ د/ هانم مصطفى محمد مصطفى البرعي

- ان قيم الثبات المركب (CR) لأبعاد المقياس تراوحت بين (1.10 - 1.05)؛

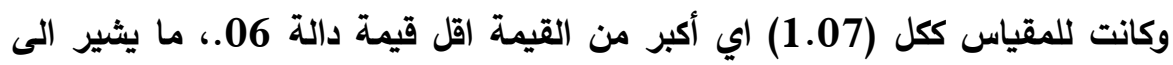

تمتع النموذج بشبات داخلي مرتفع.

يتضح مما سبق أن مقياس الشعور بالتماسك يتمتع بمعاملات صدق وثبات مقبولة مما

يثير إلى صلاحيته للتطبيق على العينة الأساسية.

نتائج الدراسـة: - 2

الفرض الأول: - الم

ينص الفرض الأول على: " يوجد مستوى مرتفع من الثعور بالسعادة الذاتية وابعادها

لاى عينة الاراسة".

للتحقق من صحة الفرض تم حساب المتوسط الحسابي، والانحراف المعياري، والمتوسط

المرجح، ومستويات الشعور بالسعادة الذاتية لأفراد عينة البحث وفق المستوى التقييمي، بحيث تكون قيمة المتوسط المرجح (ضعيفة من 2.33 - 1؛ متوسطة من 3.76 - 2.34؛ مرتفعة

من 5 - 3.77) والجدول (r I ) يوضح هذه النتائج.

جدول (r ا ( المتوسط الحسابي والانحراف المعياري ومستويات السعادة الذاتية

\begin{tabular}{|c|c|c|c|c|c|c|}
\hline الترتيب & التقييمي & المرجح & المعياري & الحستبي & العبارات & المتغيرات \\
\hline 5 & مرتفعة & 3.8 & 4.81 & 22.80 & 6 & الرضا الأكاديمي \\
\hline 4 & مرتفعة & 3.80 & 4.80 & 22.85 & 6 & المثابرة الاكاديمية \\
\hline 3 & مرتفعة & 3.86 & 5.15 & 23.13 & 6 & الارتباط بالجامعة \\
\hline 2 & مرتفعة & 3.93 & 4.60 & 23.60 & 6 & الاكادايمية \\
\hline 1 & مرتفعة & 4.20 & 4.55 & 25.18 & 6 & الامتنان للكلية \\
\hline & مرتفعة & 3.92 & 21.26 & 117.55 & 30 & السعادة الألتية \\
\hline
\end{tabular}

يتضح من الجدول (r I) أن المستوى التقييمي للشعور بالسعادة الذاتية جاء مرتفعاً

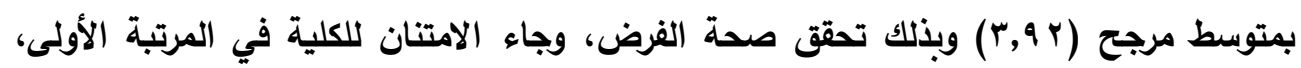
بينما جاء الرضا الأكاديمي في المرتبة الأخيرة، وجاءت المتوسطات المرجحة لأبعاد السعادة الأتية بقيم متقاربة، أي أن الفروق طفيفة جدًا بينها.

Ryan et al. ) ويتفق ذلك مع ما دلت عليه نظرية تقرير المصير للسعادة الذاتية

1996؛ Deci and Ryan, 2000, as cited In Burr et al., 2011 في أن تمتع 


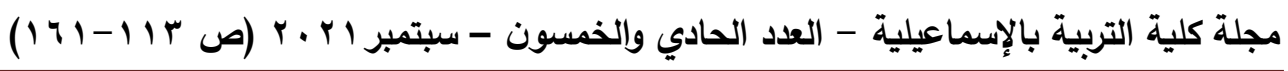
الفرد بالطموحات الجوهرية (أي السعي وراء قبول الذات والانتماء مع الآخرين، والمساهمة في المجتمع) يؤدي الى تعزيز السعادة لايهم، حيث أنه يلبي الاحتياجات الأساسية للكفاءة والاستقلالية والعلاقات. كما تتفق تلك النتائج مع دراسة سالم (1 ( . . التي توصلت الي ارتفاع

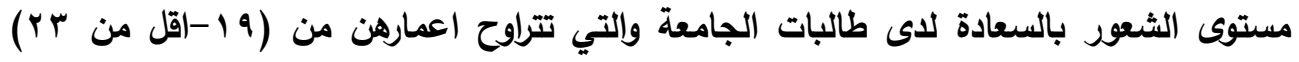

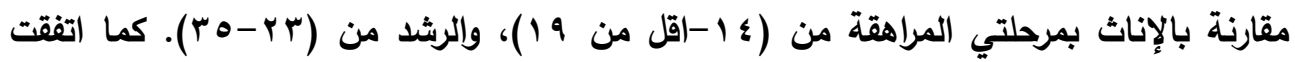

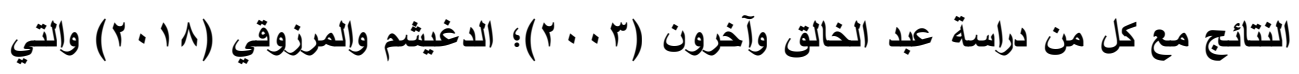
استتجت وجود مستوى مرتفع من السعادة لاى طالبات الجامعة بدولة الكويت. ويتفق ترتيب ابعاد

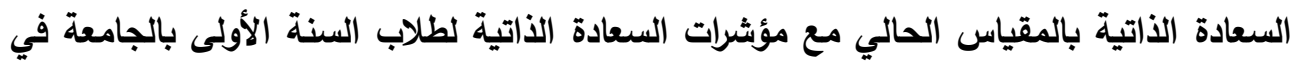
دراسة بوثا وآخرون (Botha et al,. 2019) والتي أظهرت النتائج خمس مؤشرات للسعادة الأتية في مجتمع الطلاب هي: (1) السعادة العاطفية، والتي تحدد من خلال حالات التأثير الإيجابي والسلبي، والرضا عن الحياة والجامعة؛ (Y) السعادة النفسية للمعنى، وتظهر من خلال

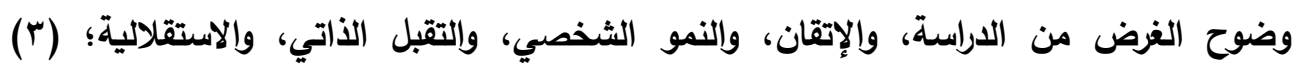

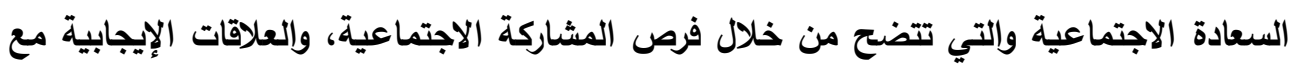
الآخرين، والثمولية من خلال التعرض للتنوع، وقبول الآخرين والثعور بالانتماء؛ ( ( ) المؤشرات الروحية، وتظهر من خلال فرص الانخراط في الروحانيات والممارسات؛ و (ه) السعادة الجسدية، وتحدث من خلال أنماط النوم والعادات الغذائية وعوامل النشاط البدني.

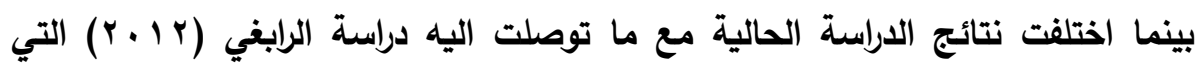
اثارت الى انخفاض مستوى الثعور بالسعادة لاى طالبات الجامعة بمحافظة جدة بالسعودية.

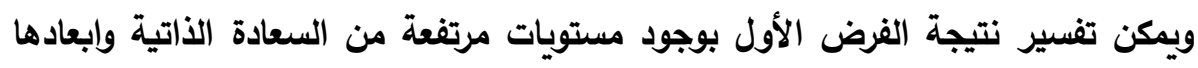
لاى طالبات الجامعة، لشعورهن بالامتنان تجاه جامعتهن التي وفرت حياة جامعية داعمة من الناون الأساتذة والعاملين والطالبات، ساعدتهن على الإنجاز الأكاديمي والثعور بالكفاءة الذاتية بالمجال

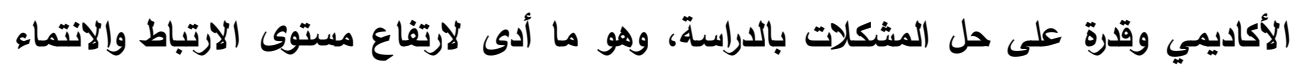
للجامعة وإنشطتها الصفية واللاصفية، كما يؤدي الى الشعور بالإصرار والمثابرة للإنجاز، والوصول للتفوق الاكاديمي ببذل كافة الجهود الممكنة بأنشطة المقررات الدراسية، ويكون حصيلة ذلك الثعور بالرضا الاكاديمي، والسعادة بالخبرة والتخصص والأنثطة الأكاديمية. 
السعادة الذاتية وعلاقتها بالشعور بالتماسك ------ د/ هانم مصطفى محمد مصطفى البرعي

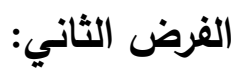

ينص الفرض الثاني على: " يوجد مستوى متوسط من الشعور بالتماسك وابعاده لاى عينة

الدراسة".

للتحقق من صحة الفرض تم حساب المتوسط الحسابي، والانحراف المعياري، والمتوسط

المرجح، ومستويات الشعور بالتماسك وابعاده لأفراد عينة البحث وفق المستوى التقييمي (تكون قيمة المتوسط المرجح ضعيفة من 2 - 1؛ متوسطة من 3 - 2.1؛ مرتفعة من 4 - 3.1) والجدول (ء 1) يوضح هذه النتائج.

\begin{tabular}{|c|c|c|c|c|c|c|}
\hline الترتيب & التقيتوى بالتم & المتوسط & الانحراف الم & الحستوسب & العبار & المتغيرات \\
\hline & متوسطة & 2.24 & 2.86 & 11.20 & 5 & الوضوح \\
\hline & متوسطة & 2.40 & 1.93 & 9.58 & 4 & قابلية الإدارة \\
\hline & مرتفعة & 4.12 & 2.18 & 12.35 & 3 & فهم المعنى \\
\hline \multicolumn{2}{|c|}{ متوسطة } & 2.76 & 5.27 & 33.12 & 12 & بالتماسكور \\
\hline
\end{tabular}

يتضح من الجدول (ع 1) أن المستوى التقييمي للثعور بالتماسك جاء متوسطا بمتوسط

مرجح (2.76) وبذلك تحقق صحة الفرض، وجاء بعد فهم المعنى في المرتبة الأولى، وفي المرتبة الثانية بعد قابلية الإدارة، بينما جاء بعد الوضوح في المرتبة الاخيرة. وتتفق نتائج

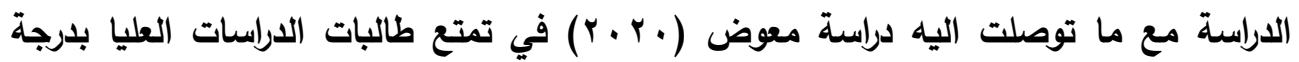
متوسطة من الشعور بالتماسك. كما يتفق ذلك مع ما توصلت إليه دراسة كواسة ومحمود

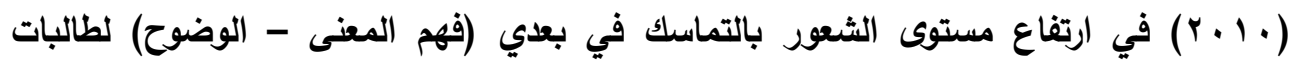
الجامعة بالسعودية ومصر مقارنة بالطلاب. بينما اختلفت النتائج مع دراسة لوي وابل وآخدي آخرون والتي توصلت الى وجود مستوى منخفض من الثعور بالتماسك غير (Luibl et al., 2021) دال احصائيا لاى طالبات الفرقة الأولى بكلية الطب. كما يتفق مع ما أشار الية انتونوفيسكي لوني

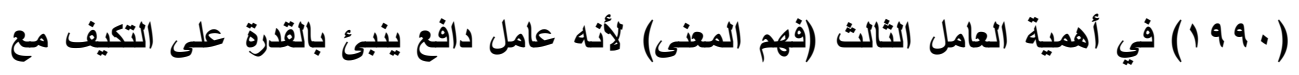
(البيئة) (Saravia et al., 2014, 35) فعملية الثعور بالتماسك تعتمد على تفسير الفرد للمؤثرات الخارجية، حيث كلما كان تفسير الفرد يقلل من قيمة الضغط الخارجي، ويزيد من إدارة الفرد على حياته زاد الثعور بالتماسك تجاه المسببات للضغوط (معوض، ب r). 


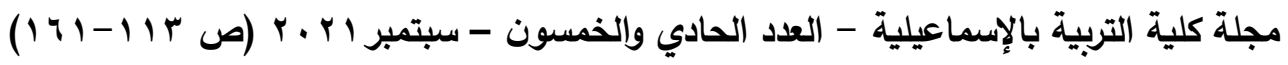
ويمكن تفسير الفرض الثاني في وجود مستوى متوسط من الثعور بالتماسك وأبعاده عدا

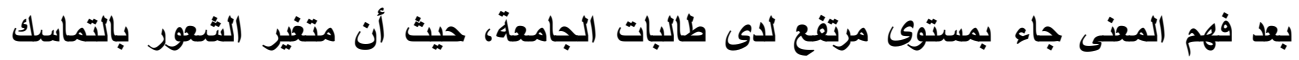
يعتمد في مكوناته على بعدين: أحدهما أدائي، والأخر معرفي وهما (قابلية الإدارة، والوضوح)

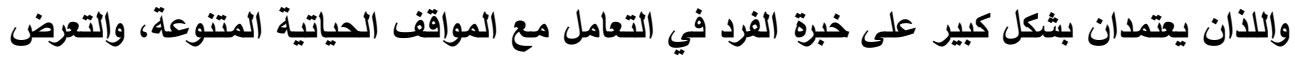
لها بثكل كبير، وقدرة الفرد على اجتياز التحديات وإدارة الضغوط بنجاح، وتقييم الفرد وإدراكه لإمكاناته في تخطي هذه الصعوبات، ما يساعد الفرد على تكوين توجه إيجابي لذاته وشعوره بالتماسك. ولأن حياة الطالبة الاكاديمية يقل فيها التنوع الخبراتي للمواقف والمشكلات مقارنة بمثكلات الحياة الجامعية، ما أدى لتقيمه بثكل متوسط من الطالبات على إجابات المقياس؛ بينما ارتفع تقييم الطالبات لبعد فهم المعنى وهو مكون تحفيزي مرتبط بتقييم الطالبات لنواتج الخبرة بالحياة الجامعية ومدى تمكنهن من النجاح الأكاديمي والأي منحهن الأمل لنجاحهن بالحياة المستقبلية والتوجه لوضع أهداف يمكنهن السعي لتحقيقها بالمستقبل. الفرض الثالث: ان

ينص الفرض الثالث على: " توجد علاقة ارتباطية موجبة دالة احصائيا بين السعادة

الأتية والشعور بالتماسك لاى عينة الدراسة". للتحقق من صحة هذا الفرض تم حساب معامل ارتباط بيرسون بين درجات أفراد العينة في

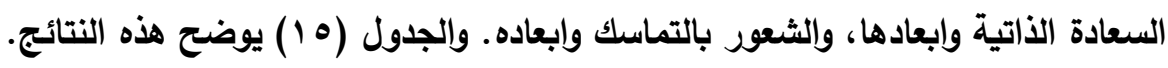
جدول (0 1) قيم معاملات الارتباط بين درجات أفراد العينة في السعادة الذاتية وأبعادها، والثعور بالتماسك وأبعاده

\begin{tabular}{|c|c|c|c|c|c|c|}
\hline الألتعادة & للالامتنان & الاكادايمية الألتية & بالجامعة & الاكاديمية & الأكاديمي & المتغيرات \\
\hline $.159 * *$ & $.108 * *$ & $.147^{* * *}$ & $.134 * *$ & $.161 \% *$ & $.152 * *$ & الوضوح \\
\hline .080 & .056 & .057 & .101 & .083 & .054 & قابلية الإدارة \\
\hline $.469 * *$ & $.377 * *$ & $.445 * *$ & $.435 * *$ & $.422 * *$ & $.393 * *$ & فهم المعنى \\
\hline $.310 * *$ & $.235^{* *}$ & $.285 * *$ & $.290 * *$ & $.293 * *$ & $.265^{* *}$ & بالتماسك \\
\hline
\end{tabular}

يتضح من الجدول (0 10) تحقق الفرض الثالث جزئيا حيث وجدت علاقات ارتباطية موجبة دالة احصائيا بين السعادة الذاتية وابعادها والثعور بالتماسك وابعاده، عدا البعد الثاني (قابلية

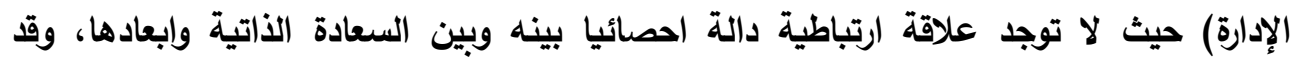

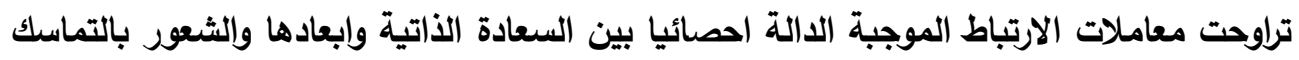


السعادة الأتية وعلاقتها بالثعور بالتماسك ------ د/ هانم مصطفى محمد مصطفى البرعي

وبعدي (الوضوح، وفهم المعنى) بين 108.- 469. وجميعها دالة عند مستوى دلالة معنوية

تتفق النتائج السابقة مع نتائج دراسة كامل (Kamel, 2001) حيث أشارت نتائج الاراسة إلى أن الثعور بالتماسك يعد متغير وسيط بين السعادة النفسية والثعور بالمدن، فهو يقوم بدور المنظم او المعُل بين المواقف الضاغطة والتوافق النفسي، حيث تعمل المستويات المرتفعة من الثعور بالتماسك كمصدات للضغوط. وهو ما توصلت إليه دراسة اولسون وآخرون (Olsson et al., 2008) يعمل الثعور بالتماسك كمتغير وسيط بين المخاطر التراكمية والسعادة، ويتضح ذلك بالداسات التحليلية الطولية. وأوضحت دراسة فيك وآخرون (Wijk et al., 2020) هذه الكيفية لمؤشرات الثعور بالتماسك (الوضوح، قابلية الإدارة، وفهم المعنى) حيث أنها تعمل كميسرات من أجل

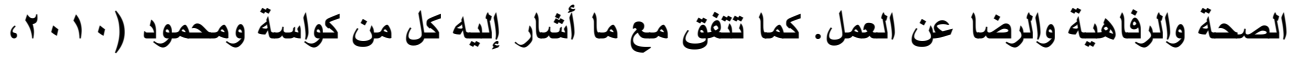

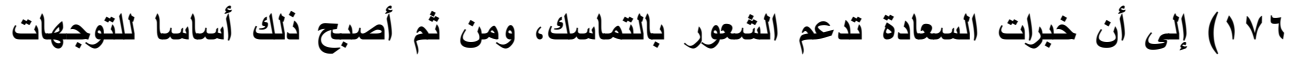
الصحية في الطب الوقائي من خلال تبني الاستراتيجيات الفعالة لتحسين الصحة والسعادة للفرد، حيث أن تحسين مستوى الثعور بالتماسك يسهم بثكل فعال في تحسين الصحة النفسية للفرد. ويثير كل من سارفيا وآخرون (Saravia et al., 2014, 36) إلى أن الثعور بالتماسك يكون بمثابة عامل وقائي للفرد، يسهم في تطوير صحته النفسية والبدنية بثكل ذاتي إيجابي، كما انه يرتبط بشكل كبير بتحسين السعادة وجودة الحياة للأفراد المرضى والاصحاء ـ وهو ما دلت عليه دراسة كرامب وآخرون (Krampe et al., 2020) والتي كثفت نتائجها عن وجود علاقة بين المستويات العليا من الثعور بالتماسك والمستويات العليا من السعادة النفسية، والتي تؤدي بدورها الى خفض الضغوط. ويمكن تفسير نتائج الفرض الثالث في وجود ارتباط موجب دال احصائيا بين السعادة الذاتية وأبعاده، والثعور بالتماسك وابعاده عدا بعد الإرادة، فكما أوضحت نتائج الداراسات السابقة

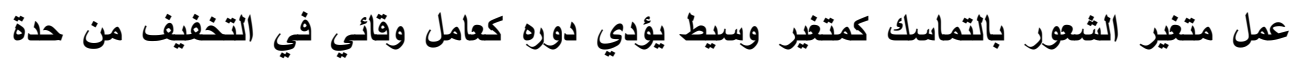
الضغوط النفسية، من خلال فهم الموقف الضغط وإيجاد المعنى من الحياة والقابلية لإدارة الأزمات. فإدراك الطالبة لقدرتها على إدارة مشكلاتها الأكاديمية يمكنها من الإنجاز والتفوق، وهو ما ينتج عنه تحسين الصحة النفسية وجودة الحياة والثعور بالسعادة الذاتية بالحياة الجامعية. 
مجلة كلية التربية بالإسماعيلية - العدد الحادي والخمسون - سبتمبر 1Y • r (ص r| 1-1 1 )

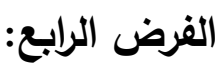

ينص الفرض الرابع على أنه": "لا يوجد تأثير دال احصائيا لكل من المستوى الدراسي وإلتخصص والحالة الاجتماعية والتفاعلات الثنائية بينهما على السعادة الأتية وأبعادها". ولاختبار صحة هذا الفرض تم استخدام تحليل التباين متعدد المتغيرات وجاءت النتائج كما

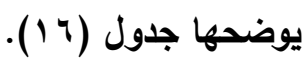

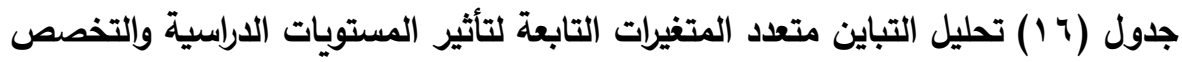
والتفاعلات الثنائية بينهما على السعادة الذاتية وأبعادها

\begin{tabular}{|c|c|c|c|c|c|c|}
\hline |الدلالةت & قيمة (ف) & المتربعات & الحرية & جموع المربعات & المتغيرات & التباين \\
\hline .270 & 1.302 & 28.08 & 4 & 112.31 & الرضا & \multirow{6}{*}{ 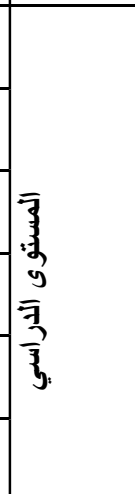 } \\
\hline .149 & 1.706 & 37.14 & 4 & 148.56 & المثابرة الاكاديمية & \\
\hline .335 & 1.147 & 29.23 & 4 & 116.95 & الارتباط بالجامعة & \\
\hline .082 & 2.090 & 41.85 & 4 & 167.43 & الأكفاءة الاكاديمية & \\
\hline .144 & 1.728 & 33.92 & 4 & 135.69 & الامتنان للكلية & \\
\hline .163 & 1.645 & $\begin{array}{ll} & 689.8 \\
27 & \\
\end{array}$ & 4 & 2759.30 & السعادة الأتية & \\
\hline .426 & .637 & 13.74 & 1 & 13.740 & الرضا الأكاديمي & \multirow{6}{*}{$\begin{array}{l}\bar{y} \\
3 \\
3\end{array}$} \\
\hline .785 & .075 & 1.62 & 1 & 1.625 & المثابرة الاكاديمية & \\
\hline .730 & .120 & 3.04 & 1 & 3.046 & الارتباط بالجامعة & \\
\hline .514 & .428 & 8.56 & 1 & 8.567 & الألتفاية الاكاديمية & \\
\hline .381 & .770 & 15.11 & 1 & 15.119 & الامتنان للكلية & \\
\hline .592 & .288 & $\begin{array}{ll} & 120.8 \\
3 & \end{array}$ & 1 & 120.837 & السعادة الأتية & \\
\hline .033 & 4.567 & 98.51 & 1 & 98.518 & الرضا الأكاديمي & \multirow{4}{*}{ 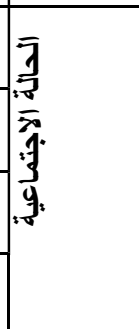 } \\
\hline .236 & 1.409 & 30.66 & 1 & 30.661 & المثابرة الاكاديمية & \\
\hline .077 & 3.148 & 80.22 & 1 & 80.222 & الارتباط بالجامعة & \\
\hline .329 & .958 & 19.18 & 1 & 19.182 & الألكفاعة الاكاديمية & \\
\hline
\end{tabular}


السعادة الذاتية وعلاقتها بالثعور بالتماسك ------ د/ هانم مصطفى محمد مصطفى البرعي

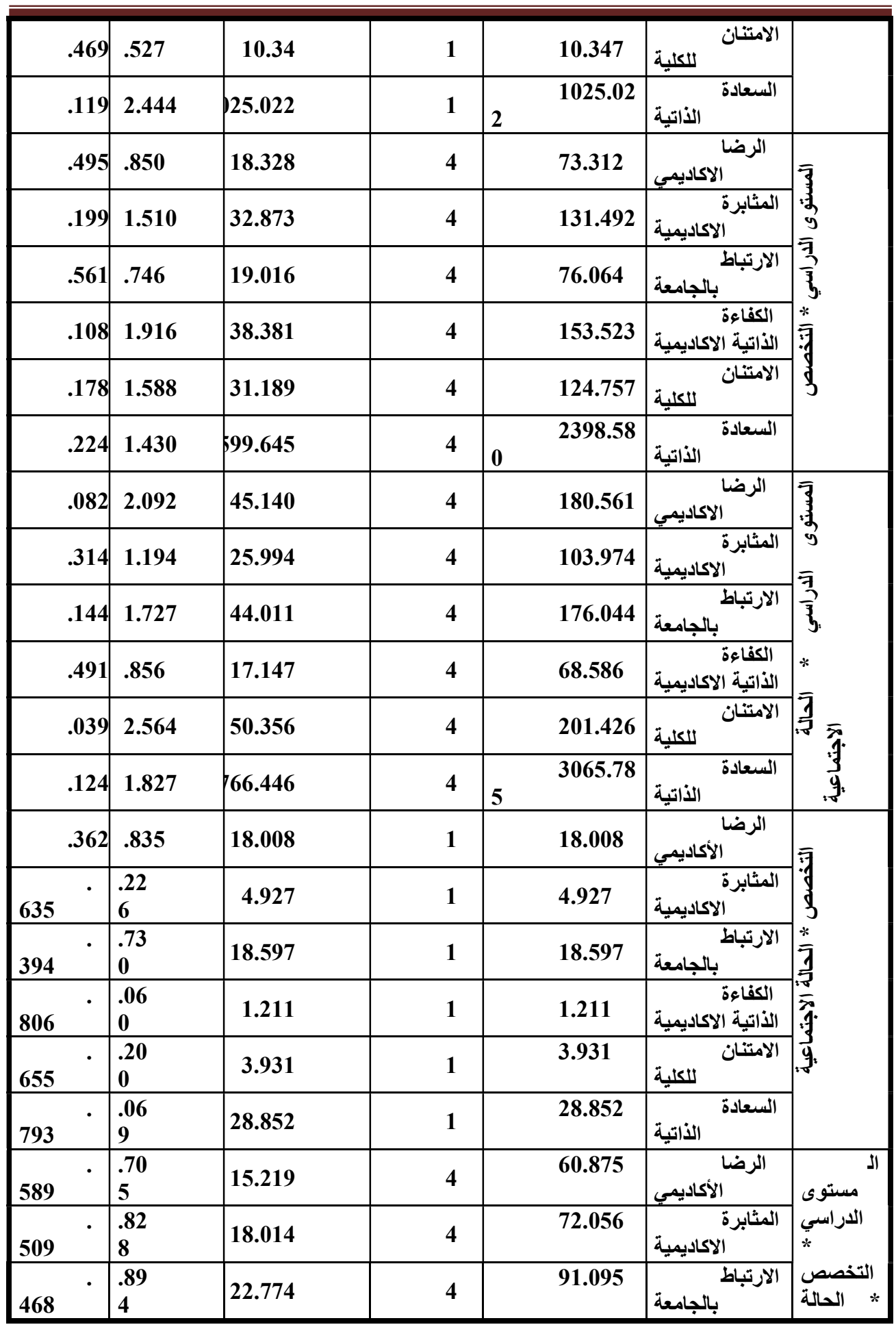




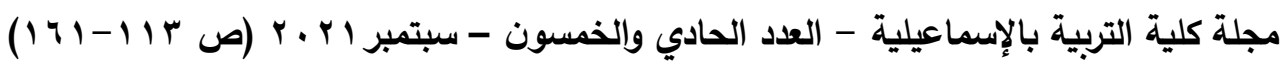

\begin{tabular}{|c|c|c|c|c|c|c|}
\hline 269 & $\begin{array}{l}1.3 \\
04\end{array}$ & 26.127 & 4 & 104.509 & الذاتية الاكاديمية & |الاجتماعية \\
\hline 528 & $\begin{array}{l}.79 \\
7\end{array}$ & 15.651 & 4 & 62.602 & الامتتان لللكلية & \\
\hline 447 & $\begin{array}{l}.93 \\
0\end{array}$ & \$90.072 & 4 & 560.287 & السعادة & \\
\hline
\end{tabular}

يتضح من الجدول (7 1) عدم وجود تأثير دال إحصائيا لكل من المستوى الدراسي،

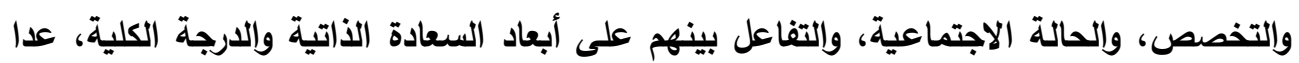
بعد الرضا الأكاديمي حيث وجد تأثير للحالة الاجتماعية، وجاء متوسطه الحسابي مساوئا (23.89) لصالح المتزوجات، كما وجد تأثير للتفاعل بين المستوى الدراسي والحالة الاجتماعية على بعد الامتنان للكلية بين حيث جاء المتوسط الحسابي مساويًا (27.48) لصالح المتزوجات

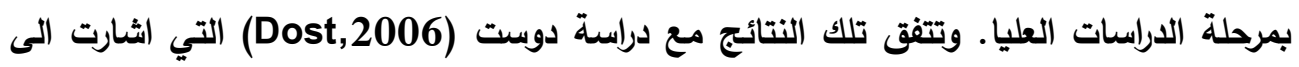

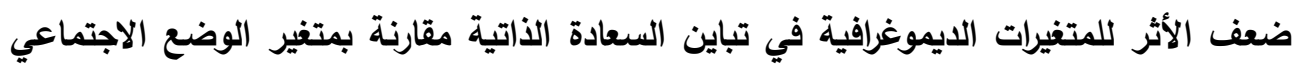

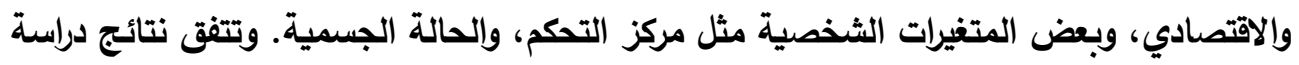

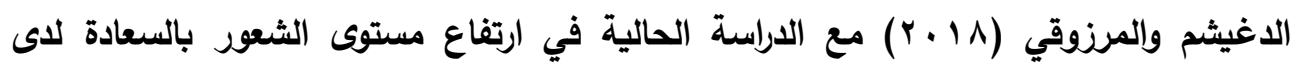

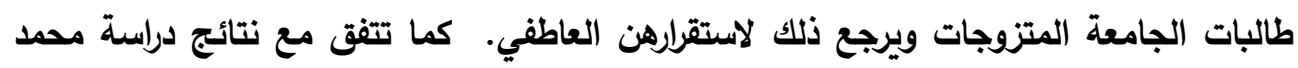

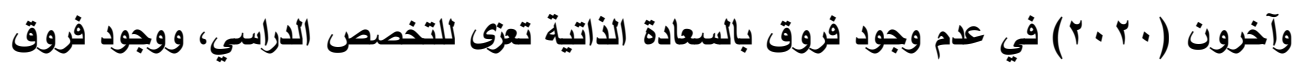
في المستوى الاراسي لصالح الفرقة الرابعة. بينما اختلفت مع دراسة عبد الرحمن (9 (19 ـ ب) والتي توصلت الى وجود فروق دالة احصائيا في الثعور بالسعادة تعزى للتخصص الدراسي لصالح التخصص العلمي. ويمكن تفسير نتائج الفرض الرابع كما أثارت نتائج الدراسات السابقة في ضعف تأثير المتغيرات الايموغرافية في السعادة الأتية عدا الحالة الاجتماعية لاى الطالبات بالجامعة، فالحياة الجامعية بما تثمله من جودة العلاقات الاجتماعية، وطبيعة الأنثطة اللاصفية، والدورات التدريبية التأهيلية للزواج ورفع مستوى كفاءة الذات، تقدم بالجامعة لكافة الطالبات باختلاف

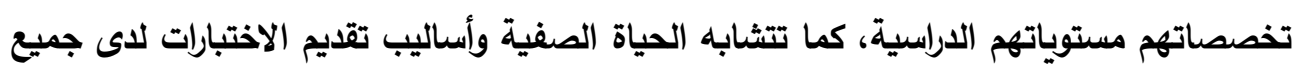
الكليات باختلافات طفيفة تبعا للتخص الاكاديمي، لذا يتساوى خبرة الطالبات باختلاف مستويات

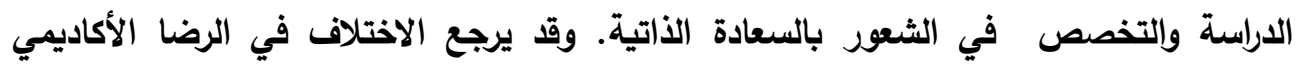

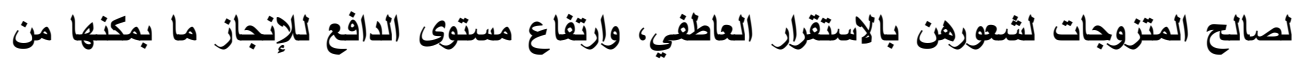
تحقيق أهدافها، ويجعلها تشعر بالرضا عن حياتها الجامعية. 
السعادة الأتية وعلاقتها بالثعور بالتماسك ------ د/ هانم مصطفى محمد مصطفى البرعي نتائج الفرض الخامس:

ينص الفرض الخامس أنه "لا يوجد تأثير دال احصائيا لكل من المستوى الدراسي والتخصص والحالة الاجتماعية والتفاعلات الثنائية والثلاثية بينهم على الثعور بالتماسك وابعاده".

لاختبار صحة هذا الفرض تم استخدام تحليل التباين متعدد المتغيرات وجاءت النتائج كما

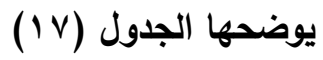
جدول (IV) تحليل التباين متعدد المتفيرات التابعة لتأثير المستوى الدراسي والتخصص والحالة الاجتماعية والتفاعلات بينهم على الثعور بالتماسك وأبعاده

\begin{tabular}{|c|c|c|c|c|c|c|}
\hline مستوى & قيمة (ف) & متروسطات $\quad$ مجموع & الدرجية & مجموع المربعات & |المتغيرات & التباين \\
\hline 001 & 4.672 & 34.821 & 4 & 139.283 & |الوضوح & \\
\hline 063 & 2.259 & 8.250 & 4 & 32.998 & قابلية & 赶 \\
\hline 031 & 2.702 & 11.105 & 4 & 44.419 & |فهن: & 当 \\
\hline 000 & 5.564 & 135.116 & 4 & 540.465 & بالتماسك & $\overline{3}$ \\
\hline 224 & 1.487 & 11.080 & 1 & 11.080 & | الوضوح & \\
\hline 101 & 2.710 & 9.897 & 1 & 9.897 & قابلية & 可 \\
\hline 310 & 1.032 & 4.243 & 1 & 4.243 & | فهنى & 3 \\
\hline 084 & 2.999 & 72.835 & 1 & 72.835 & بالتماسك & \\
\hline 804 & .061 & .458 & 1 & .458 & |الوضوح & الاجتماعية \\
\hline 197 & 1.669 & 6.096 & 1 & 6.096 & |قابابلية & \\
\hline 011 & 6.607 & 27.151 & 1 & 27.151 & | فهن: & \\
\hline 488 & .481 & 11.684 & 1 & 11.684 & |الثماستك & \\
\hline 841 & .354 & 2.640 & 4 & 10.559 & الوضوح & 量泀 \\
\hline 292 & 1.244 & 4.544 & 4 & 18.176 & قابالية & $=3$ \\
\hline 268 & 1.305 & 5.363 & 4 & 21.453 & | فهنى & $\overrightarrow{3}$ \\
\hline
\end{tabular}




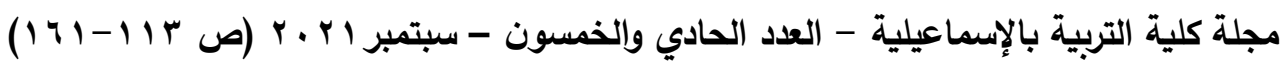

\begin{tabular}{|c|c|c|c|c|c|c|}
\hline 626 & .652 & 15.828 & 4 & 63.313 & بالتماسك & \\
\hline 873 & .307 & 2.292 & 4 & 9.167 & الوضوح & 牙牙 \\
\hline 323 & 1.173 & 4.285 & 4 & 17.139 & قالإبلية & 亭 \\
\hline 390 & 1.035 & 4.252 & 4 & 17.010 & فهن & 3. \\
\hline 341 & 1.134 & 27.542 & 4 & 110.169 & بالتماسك & $\overline{\bar{n}}$ \\
\hline 066 & 3.419 & 25.481 & 1 & 25.481 & الوضوح & تخصص ال \\
\hline 212 & 1.564 & 5.711 & 1 & 5.711 & الإبارةة & | الاجتماعية الحالة \\
\hline 298 & 1.088 & 4.473 & 1 & 4.473 & فهنج & \\
\hline 281 & 1.167 & 28.331 & 1 & 28.331 & بالتماستك & \\
\hline 713 & .531 & 3.961 & 4 & 15.843 & الوضوح & مستوى \\
\hline 404 & 1.007 & 3.678 & 4 & 14.713 & قالإدارة & * الدراسي \\
\hline 034 & 2.642 & 10.857 & 4 & 43.428 & فهنج & * التضصلة \\
\hline 405 & 1.006 & 24.417 & 4 & 97.668 & بالتماسك & الاجتماعية \\
\hline
\end{tabular}

يتضح من الجدول (IV) عدم صحة الفرض الخامس جزئيا حيث وجد تأثير دال إحصائيا لمتغير المستوى الدراسي على بعدي الوضوح، وفهم المعنى، واللارجة الكلية للشعور بالتماسك، وجاء متوسطه الحسابي مساويُا (12.65) لبعد الوضوح، و(13.37) لبعد فهم المعنى، و(35.98) للارجة الكلية لصالح طالبات الدراسات العليا، كما وجد تأثير لمتغير الحالة الاجتماعية على بعد فهم المفنى وجاء متوسطه(12.88) لصالح المتزوجات، ووجود تأثير للتفاعل بين المستوى الاراسي والتخصص والحالة الاجتماعية على بعد فهم المعنى حيث جاء المتوسط الحسابي مساويًا (15.0) لصالح المتزوجات بالسنة الرابعة بالتخصص العلمي. Lindstrom \& Eriksson, 2005; Antonovsky \& ) ويتفق ذلك مع دراسات (Sage, 2001) الخبرة وتعلم أساليب عديدة للتوافق مع المواقف المختلفة. كما تتفق مع نتائج دراسة مصطفى لوان

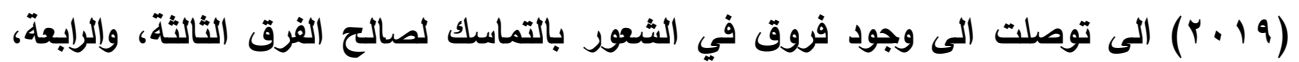


السعادة الأتية وعلاقتها بالثعور بالتماسك ------ د/ هانم مصطفى محمد مصطفى البرعي والخامسة لطلاب كلية الطب مقارنة بالفرقتين الأولى والثانية لتمكنه من مهارة التبؤ وفهم الاحداث، وزيادة القدرة على الحفاظ على الصحة النفسية. وتختلف تلك النتائج جزئيا مع دراسة

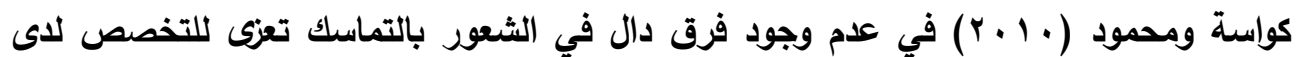
طلبة الجامعة.

ويمكن تفسير نتائج الفرض الخامس في وجود تأثير لمتغيرات السنة الاراسية، والحالة الاجتماعية والتخصص، والتفاعل بينهم على الشعور بالتماسك، وبعض الابعاد (الوضوح -فهم

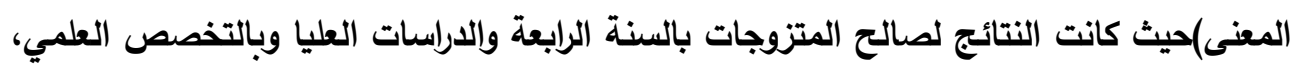
فخبرة الطالبة الجامعية بتقييم مواقف الحياة الأكاديمية، والقدرة على تفهم المشكلات، وإدارة الضغوط، والنجاح بالعلاقات الاجتماعية، تزداد بالاستقرار العاطفي وبالتقدم في العمر، لذا تتباين درجات الطالبات في مستوى الثعور بالتماسك وبعديه الوضوح و فهم المنى لصالح طالبات السنة الرابعة والدراسات العليا، وقد يعود الأثر في تباين درجات الطالبات في الثعور بالتماسك لصالح التخصص العلمي لطبيعة الأنثطة العملية التي تحفز الانتباه، والتقييم، واستخلاص النتائج بدقة عالية مما يساعد على ادراك مواقف المشكلات والأزمات بصورة إيجابية غير محبطة ويرفع مستوى الشعور بالتماسك بالحياة الأكاديمية. نتائج الفرض السادس: ينص الفرض السادس على "لا يمكن التبـؤ بالسعادة الأتية من الثعور بالتماسك وأبعاده". وللتحقق من هذا الفرض تم اسـتخدام تحليـل الانحـدار المتعدد كمـا هـي موضـحة بالجدول (1 ا ).

جدول (1 ا ) يوضح نتائج تحليل التباين الثعور بالتماسك وأبعاده على السعادة الذاتية

\begin{tabular}{|c|c|c|c|c|c|}
\hline الاحصائية & قيمة (ف) & متوسط المربعات & درجات الحرية & مجموع المربعات & مصدر \\
\hline \multirow{3}{*}{000} & \multirow{3}{*}{27.584} & 9732.717 & 3 & 29198.152 & الانحدار \\
\hline & & 352.836 & 294 & 103733.691 & البواقي \\
\hline & & & 297 & 132931.842 & المجموع \\
\hline
\end{tabular}

يتضح من الجدول (1^) ان قيمة (ف) لتباين الانحدار بلغت 27.584 وهي دالة احصائيا مما يثير الى عدم صحة الفرض السادس، وإمكانية التنبؤ بالسعادة الأتية من خلال الارجة الكلية للشعور بالتماسك وبعديه فهم المعنى، وقابلية الإدارة، بينما تم استبعاد بعد الوضوح من تحليل تباين الانحدار وجدول (9 1 ) يوضح ذلك. 


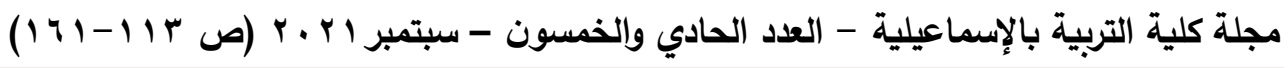
جدول (9 1) نتائج تحليل الانحدار للتنبؤ بالسعادة الذاتية من الشعور بالتماسك وأبعاده

\begin{tabular}{|c|c|c|c|c|c|}
\hline ها ودلالت & قيمة (ت) & بيتا & الخطأ المعياري & معامل الانحدار & المستغيرة \\
\hline .000 & 7.957 & & 7.686 & 61.157 & الثابت \\
\hline .963 & .046 & .004 & .961 & .045 & قالإبلية \\
\hline .000 & 5.683 & .468 & .799 & 4.539 & فهُخ \\
\hline .995 & $.006-$ & $.001-$ & .460 & $.003-$ & بالتماسكت \\
\hline
\end{tabular}

يتضح من الجدول (19) وجود دلالة إحصائية لقيمة ثابت معادلة التنبؤ بقيمة

61.157، وبعد فهم المعنى بقيمة اسهام 4.539 في السعادة الأتية، بينما لم يوجد اسهام دال لبعد قابلية الإدارة والدرجة الكلية للتماسك في السعادة الأتية، وتصبح معادلة التنبؤ للسعادة

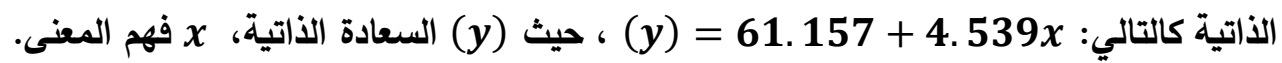

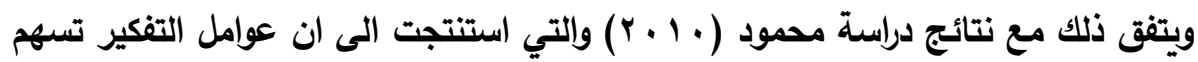
بنسبة و r, • في التباين الكلي للسعادة. وهو ما يشير الى أهمية العوامل الداخلية في الثخصية ومنها الثعور بالتماسك وما يتضمنه من فهم المعنى كنمط للتفكير بعمق، والقدرة على إدارة

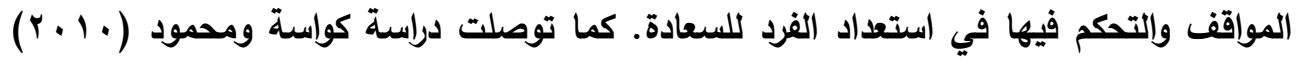
الى الاسهام النسبي لأبعاد الشعور بالتماسك على جودة الصحة النفسية لاى طلاب الجامعة

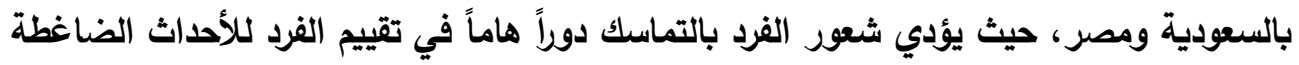
وكيفية مواجهتها بنجاح وتحقيق الصحة النفسية. وتثير يوسفي (Y. V V) الى أن الثعور بالتماسك ينشئ لاى الفرد جدار صد ودفاع يعينه على التكيف مع احداث الحياة الضاغطة والمؤلمة، ويخلق شخصية شديدة الاحتمال تستطيع مقاومة الضغوط، تجعل الفرد يعيش بحالة من التفاؤل والأمل، وتخلو حياته من القلق والاكتئاب. ويمكن تفسير نتائج الفرض السادس في إمكانية التنبؤ بالسعادة الذاتية من أحد ابعاد الثعور بالتماسك وهو فهم المعنى، فكما اشارت نتائج الفرض الثالث في وجود علاقة ارتباطية موجبة دالة احصائيا بين السعادة الذاتية والثعور بالتماسك وابعاده (الوضوح، وفهم المعنى) لاى طالبات الجامعة، فتمكن الطالبة من إدارة حياتها الجامعية، وقدرتها على تجاوز الأزمات والضغوط الصفية والأكاديمية، واستيعابها للمغزى والدوافع التي تقع خلف المواقف بثكل إيجابي، يرفع من مستوى الثعور بالأتية ويحقق لها الإنجاز والكفاءة الأكاديمية ويزيد من الثعور بالامتنان تجاه الجامعة والعاملين فيها، والعيش بجودة حياة جامعية. 
السعادة الذاتية وعلاقتها بالثعور بالتماسك ------ د/ هانم مصطفى محمد مصطفى البرعي التوصيات التربوية:

1. اعداد برامج ارشادية لطالبات الجامعة لتحسين مستوى الشعور بالتماسك، وتعزيز مستويات الشعور بالمعنى والإدارة لمواقف الضغوط.

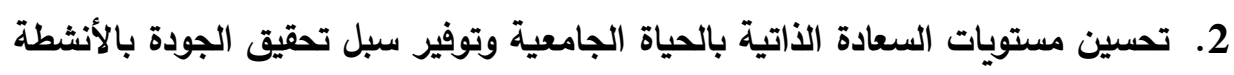

$$
\text { الصفية وإللاصفية والعلاقات الاجتماعية. }
$$

3. دراسة مستويات الضغوط الأكاديمية وأسبابها والعمل على خفضها من خلهاهيها خلال البرامج

$$
\text { الإرشادية المتخصصة. }
$$

4. تحسين مستويات السعادة الاتية ومستوى الثعور بالتماسك بزيادة الاهتمام بالمستويات

الاراسية المختلفة والتخصصات العلمية بالجامعة لاى المتزوجات وغير المتزوجات.

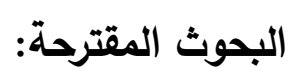

1. دراسة السعادة الذاتية لدى طلاب الجامعة وفق العديد من المتغيرات الديموغرافية

$$
\text { والنفسية والاجتماعية. }
$$

2. دراسة الثعور بالتماسك وفق العديد من المتغيرات الديموغرافية والنفسية والاجتماعية.

3. اعداد مقاييس عربية للسعادة الذاتية والشعور بالتماسك تناسب الفئات العمرية المختلفة.

4. التحقق من فعالية برنامج ارشادي لتحسين مستوى السعادة الذاتية لاى طلاب الجامعة باستخدام مؤشرات الثعور بالتماسك. 


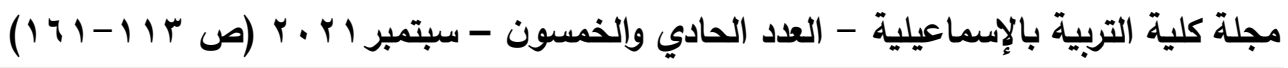
المراجع

ابو هاشم، السيد محمد ( • + †، يناير). النموذج البنائي للعلاقات بين السعادة النفسية والعوامل الكبرى للثخصية وتقدير الذات والمساندة الاجتماعية لاى طلاب الجامعة، مجلة كلية

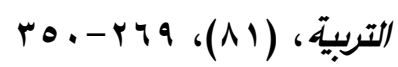

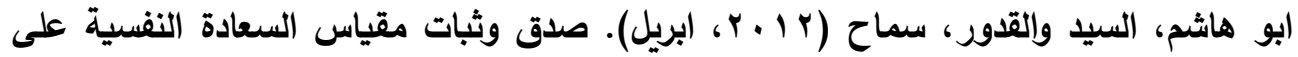
عينات مصرية وسعودية وسورية من طلاب الجامعة، دراسات تربوية ونفسية، مجلة كلية

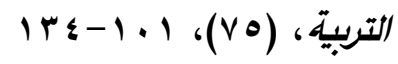

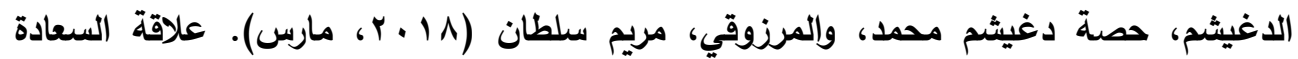
ببعض الخصائص الايموجرافية لاى طالبات كلية التربية الأساسية وجامعة الكويت، مجلة

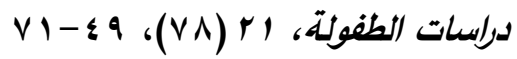

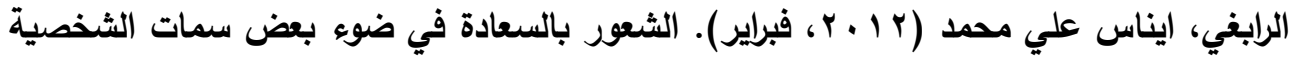

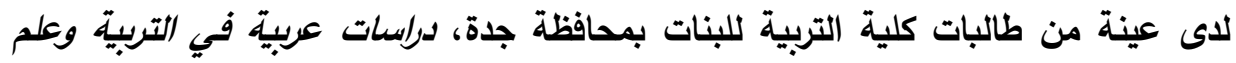

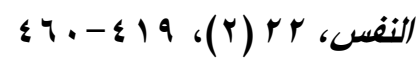

سالم، سهير محمد (1 (. ب). السعادة وعلاقتها ببعض المتغيرات النفسية: دراسة ارتقائية ارتباطية مقارنة، رسالة ماجستير منشورة، معهد الدراسات والبحوث التربوية، جامعة القاهرة. www.askzad.com/Bibliographic?service=3\&key=PAD_Bibliographi c_Content\&imageName $=$ BK 00010736-001

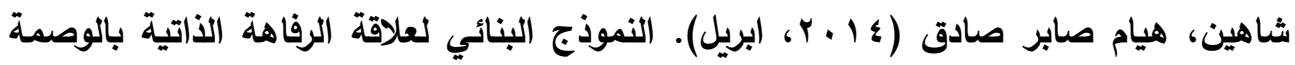

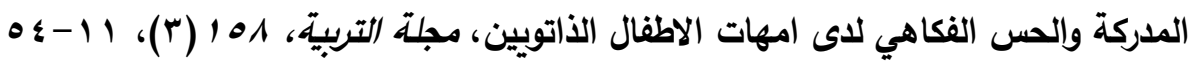
صديق، محمد السيد (q. ...، (ابريل). التدفق وعلاقته ببعض العوامل النفسية لدى طلاب

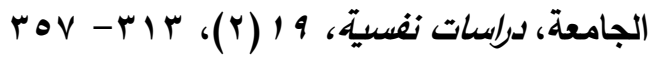

عبد الخالق، احمد محم، الثطبي، وتغريل سليمان، والذيب، سماح أحمد، وعباس، سوسن

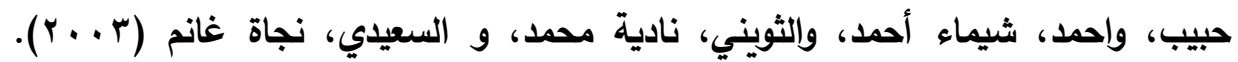

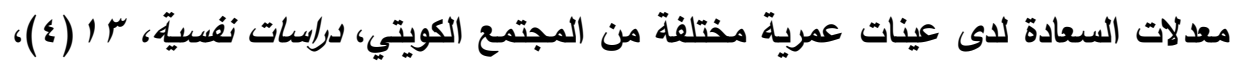
IIr-ONI 
السعادة الأتية وعلاقتها بالثعور بالتماسك ------ د/ هانم مصطفى محمد مصطفى البرعي

عبد الرحمن، حنان أحمد (19 ـ r). السعادة وعلاقتها ببعض المتفيرات النفسية لاى طلاب الجامعة في ضوء بعض المتغيرات الديموجرافية، مجلة قطاع الدراسات الإنسانية، ( (ب)،

rY $\{-O r$

عصفور، ايمان حسنين (Y (1)، اكتوبر). تنشيط المناعة النفسية لتنمية مهارات التفكير الإيجابي وخفض قلق التدريس لاى الطالبات المعلمات شعبة الفلسفة والاجتماع، دراسات

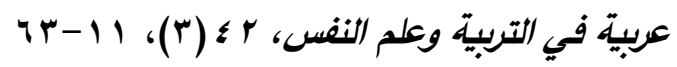

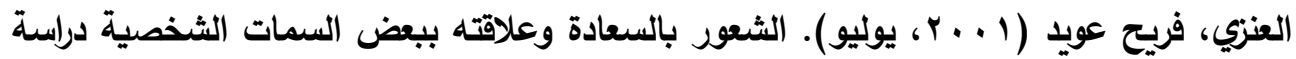

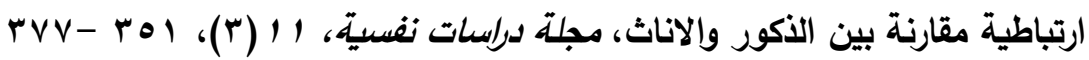

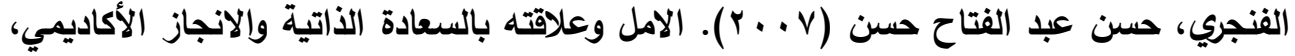
المؤتمر العلمي الثامن للتربية (جودة واعتماد مؤسسات التعليم العام في الوطن العربي) -

$$
\text { مصر، (r) }
$$

كواسد، عزت عبد الله ومحمود، محمد يوسف (• ( • ب، ابريل). الثعور بالتماسك ازاء المواقف الضاغطة وعلاقته بجودة الصحة النفسية لاى طلاب الجامعة: دراسة عبر ثقافية (مصر -

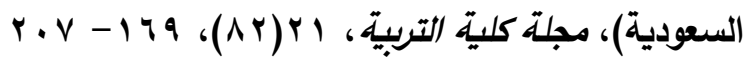

محد، سارة احمد، وشوكت، عواطف إبراهيم، ومصطفى، هدى نصر (·r • (Y). الرفاهة الذاتية

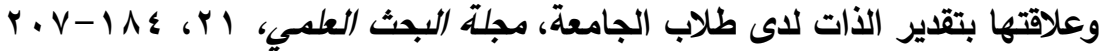

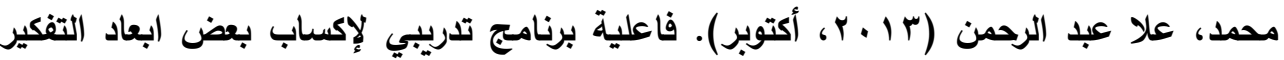

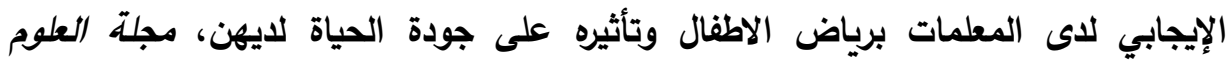

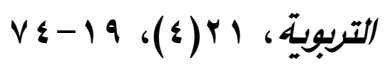

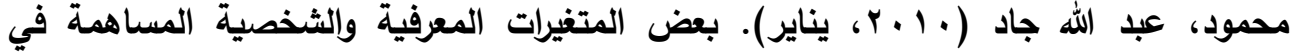

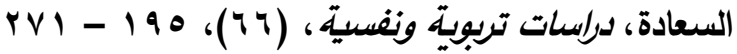

مصطفى، منال محمود محمد (9 19 • ؟، اكتوبر). النموذج البنائي للعلاقات السببية بين الثعور بالتماسك الأمل المسهمة في الإرهاق الأكاديمي لاى طلبة كلية الطب-جامعة القاهرة، المجلة

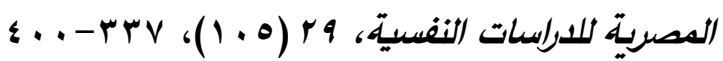

معوض، مروة نشأت (·r · r). الثعور بالتماسك النفسي والإحساس بالمسئولية الاجتماعية كمنبئات بجودة الصداقة لاى طلاب الدراسات العليا، مجلة كلية التربية بالمنصورة، باتية

$$
10.9-1 \leq 74,(r) 1.9
$$




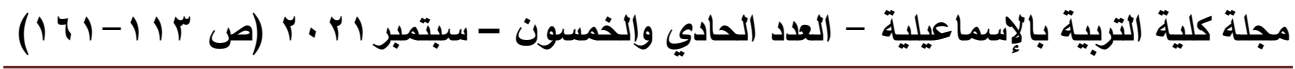

يوسفي، حدة (YV. YV، مارس). الثعور بالتماسك كمورد صحي: قراءة في المفهوم والابعاد

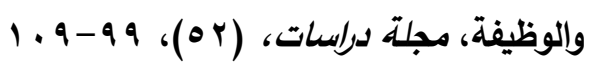

Antonovsky, H. \& Sage, S. (2001). The Development of Sense of Coherence and its impact on Responses to Stress Situation, The Journal of Social psychology, 126(2), 213-225

Botha, B., Mostert, K., \& Jacobs, M. (2019). Exploring indicators of subjective well-being for first-year University student, Journal of psychology in Africa. 29(5), 80-490.

Brown, T. A. (2015). Confirmatory Factor Analysis for Applied Research, Second Edition, New York, Division of Guilford Publication.

Bowman, B. J. (1996). Cross-Cultural validation of Antonovsky's sense of Coherence scale, Journal of clinical psychology, John Willy \& Sons, 52(2), 547-549

Carpentier, J., Mageau, G.A., \& Vallerand, R.J. (2011). Rumination and flow: Why do people with a more harmonious passion experience higher well-being?, Journal of Happiness Studies, 13, 501-518

Burr, A., Santo, J.B. \& Pushkar, D. (2011). Affective Well-Being in Retirement: The Influence of Values, Money, and Health Across Three Years, J Happiness Stud, 12,17-40

Chen, F. F., Jing, y., Hayes, A. \& Lee, J. M. (2012). Two Concepts or Two Approaches? A Bifactor Analysis of Psychological and Subjective Well-Being, Published online: Journal of Happiness Studies, 14, 1033-1068

Chilton, G. \& Alexandria, V.A. (2013). Art therapy and flow : A review of the literature and applications, Journal of American Association, $30(2), 64-70$

Csikszentmihalyi, M. (1994). The Evolving Self: A Psychology for the Third Millennium. HarperCollins Publishers.

Davies, F.J. (2009). The power of positive thinking: The effects of selfesteem, explanatory style, and trait hope on emotional well-being, University of Wollongong, Research Online, https://ro.uow.edu.au/theses, 26/8/2020

Dost, M.T. (2006). Subjective Well-Being among University students, Hacettepe OniversiUsi Eiitim FakUttesi Dergisi 31(31), 188-197

Eaude, T. (2009). Happiness, emotional well-being and mental health what has children 's spirituality to offer?, International Journal of children's spirituality, 14(3), 187-196 
السعادة الذاتية وعلاقتها بالثعور بالتماسك ------ د/ هانم مصطفى محمد مصطفى البرعي

Eriksson, M. \& Lindstrom, B. (2005). Validity of Antonovsky sense of coherence scale: A systematic review. Journal of Epidemiology Community Health, 59, 460-466

Eriksson, M. \& Lindstrom, B. (2017). Validity of Antonovsky's sense of coherence scale: a systematic review, http://jech.bmj.com/ 8/6/2017

Howard, F. (2008, June) Managing stress or enhancing wellbeing? positive psychology's contributions to clinical supervision, Australian psychologist, 43(2), 105-113, https://doi.org/10.1080/00050060801978647

Jakobsson, U. (2011). Testing Construct Validity of the 13-Item Sense of Coherence Scale in a Sample of Older People, The Open Geriatric Medicine Journal, (4), 6-13

Kamel, G. (2001) Is sense of coherence a mediator between adversity and psychological well-being in adults?, Stress and Health, John Wiley \& Sons, (17), 77-83

Kashdan, T.B. Diener, R.B. \& King, L.A. (2008). Reconsidering happiness: the costs of distinguishing between hedonics and eudaimonia, The Journal of Positive Psychology, 3(4), 219-233

Keyes, C.L.M., Shmotkin, D., \& Ryff, C.D. (2002). Optimizing WellBeing: The Empirical Encounter of Two Traditions, Journal of Personality and Social Psychology, 82(6), 1007-1022

Krampe, H., Goerling, U., Spies, C., D., Gerhards, S. K., Enge, S., Salz, A. L., Kerper, L. F., \& Schnell, T. (2020). Sense of coherence, mental well-being and perceived preoperative hospital and surgery related stress in surgical patients with malignant, benign, and no neoplasms, BMC Psychiatry, 20(567), 1-13. https://doi.org/10.1186/s12888-020-02953-x

Litwin, H. \& Ezra, S.S. (2010) Social Network Type and Subjective Wellbeing in a National Sample of Older Americans, Oxford University Press on behalf of The Gerontological Society of America, 51(3), 379-388

Liu, J. (2021). Social support mediates the effect of forgiveness on subjective wellbeing in college students, Social Behavior and Personality, 49(5). https://doi.org/10.2224/sbp.10177

Luibl, L., Traversari, J., Paulsen, F., Scholz, M., \& Burger, P. (2021). Resilience and sense of coherence in first year medical students - a cross-sectional study, BMC Medical Education, 21(142), 2-10. https://doi.org/10.1186/s12909-021-02571-5

Olsson, M.B.; Larsman, P. \& Hwang, P.C. (2008). Relationship among risk, Sense of coherence and well-being in parents of children with 


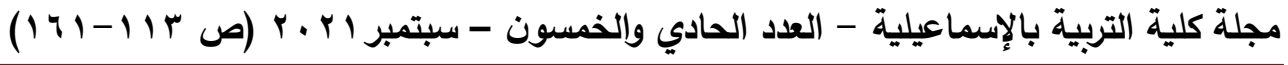
and without intellectual disabilities, Journal of policy and practice in intellectual disabilities, 5(4), 227-236

Pantuza, J., Alexandre, I., Medeiros, A., Marinho, A., \& Teixeira, L. (2019). Sense of Coherence and the fear of public speaking in university students, CoDAS, 32(5), 3-8. https://doi:10.1590/23171782/20202019071

Renshaw, T.L. \& Bolognino, S. J. (2016). The College Student Subjective Wellbeing Questionnaire: A Brief, Multidimensional Measure of Undergraduate's Covitality, Happiness Stud, (17), 463484

Pretorius, M. \& Blaauw, D. (2020). Financial Challenges and the Subjective Well-being of First-year Students at a Comprehensive South African University, Journal of Student Affairs in Africa, 8(1), 47-63

Saravia, J.C., Iberico, C. \& Yearwood, K. (2014). Validation of Sence Of Coherence (SOC) 13-Item Scale in Peruvina Sample, Journal of Behavior, Health \& Social Issues, 6(2), 35-44

Scoffham, S. \& Barnes, J. (2011). Happiness matters: towards a pedagogy of happiness and well-being, The Curriculum Journal, 22(4), 535-548

Tomas, J.M, Sancho, P., Melendez, J.C., \& Mayordomo, T. (2011). Resilience and coping as predictors of general well - being in the elderly: A structural equation modeling approach, Aging \& Mental Health, 16(3), 318-329

Wang, Y. (2020). College students' trait gratitude and subjective wellbeing mediated by basic psychological needs, Social Behavior and Personality, 48(4). https://doi.org/10.2224/sbp.8904

Wijk, K., Bergsten, E. L., \& Hallman, D. M. (2020). Sense of Coherence, Health, Well-Being, and Work Satisfaction before and after Implementing Activity-Based Workplaces, International Journal of Environmental Research and Public Health, 17(5250), 115. https://doi:10.3390/ijerph17145250 
السعادة الذاتية وعلاقتها بالثعور بالتماسك ------ د/ هانم مصطفى محمد مصطفى البرعي

الملخص

استهدفت الدراسة الحالية دراسة العلاقة بين السعادة الذاتية والثعور بالتماسك، وكذلك

دراسة أثر بعض المتغيرات الايموغرافية مثل (المستوى الدراسي - التخصص - الحالة الاجتماعية) والتفاعل بينهم على كل من السعادة الذاتية والثعور بالتماسك، والتعرف على مدى اسهام الشعور بالتماسك في التنبؤ بالسعادة الذاتية لاى عينة من (^^^) طالبة من جامعة الملك فيصل بالمملكة العربية السعودية، باستخدام استبيان السعادة الذاتية اعداد Renshaw) (A Bolognino, 2016) تعريب وتقنين الباحثة، ومقياس الثعور بالتماسك المختصر اعداد(Antonovsky, 1987) تعريب وتقنين الباحثة، وبعد التحقق من خصائصهما السيكومترية للمقاييس، ومعالجة البيانات إحصائيا تم التوصل الى: وجود مستوى مرتفع من السعادة الأتية، ومستوى متوسط من الثعور بالتماسك لاى طالبات الجامعة، كما توجد علاقة

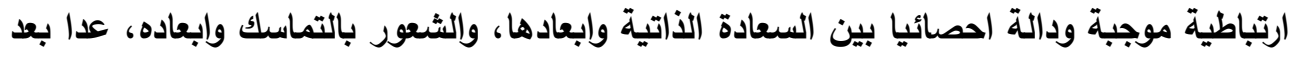

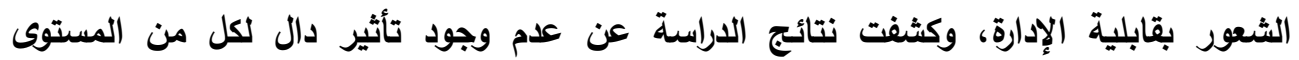

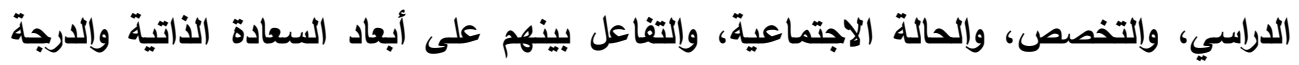

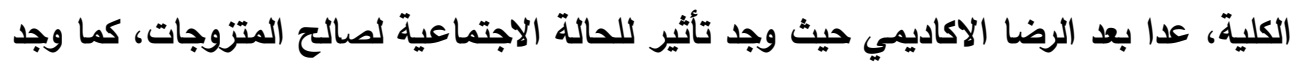
تأثير للتفاعل بين المستوى الدراسي والحالة الاجتماعية على بعد الامتنان للكلية لصالح

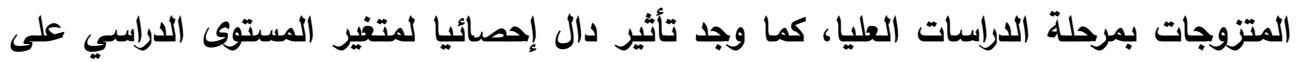
بعدي الوضوح، وفهم المعنى، والدرجة الكلية للثعور بالتماسك لصالح طالبات الدراسات العليا، وكذلك تأثير دال احصائيا لمتغير الحالة الاجتماعية على بعد فهم المعنى لصالح المتزوجات، وفئ ووجود تأثير للتفاعل بين المستوى الاراسي والتخصص والحالة الاجتماعية على بعد فهم المعنى لصالح المتزوجات بالسنة الرابعة بالتخصص العلمي، كما اثلارت النتائج الى اسهام بعد فهم المعنى في السعادة الذاتية، بينما لم يوجد اسهام دال لبعدي الوضوح وقابلية الإدارة، والدرجة لإنة الكلية للتماسك في السعادة الذاتية. الكلمات المفتاحية: السعادة الذاتية - الثعور بالتماسك - علم النفس الإيجابي - طالبات الجامعة - التنبؤ 


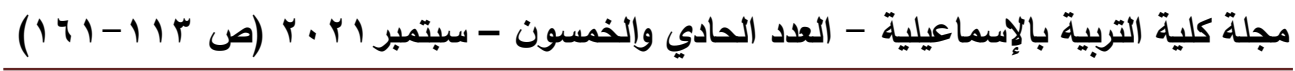

\section{Subjective Well-being and its relationship with} sense of coherence Among Students University

\section{Abstract:}

The current study aimed to study the relationship between subjective well-being and sense of coherence; the impact of (school level, specialization, social status) and the interaction between them on subjective well-being and sense of coherence, and predicting subjective well-being from sense of coherence in a sample of (298) female students from King Faisal University in Saudi Arabia, using the subjective wellbeing questionnaire by (Renshaw \& Bolognino, 2016), and the brief sense of coherence scale by (Antonovsky, 1987) Arabization by the researcher, The finding: There was a high level of subjective well-being, and a medium level of sense of coherence; positive correlation between subjective well-being and sense of coherence and its dimensions, except for manageability; no significant effect for academic level, specialization, social status, and the interaction between them on subjective well-being except for satisfaction Academic; there was an effect of social status for married women; there was an effect of interaction between academic level and social status on gratitude for married women at the postgraduate level; significant effect of the academic level variable on comprehensibility, meaningfulness, and sense of coherence for female students; significant effect of the social status on the understanding of meaning for married women; no effect of the interaction between academic level, specialization, and social status on meaningfulness for married women in the fourth year of scientific specialization; a contribution of meaningfulness to subjective well-being, while There was no significant contribution to comprehensibility and manageability, and the sense coherence in subjective well-being.

Key words: Subjective well-being, Sense of Coherence, Positive Psychology, Student University, Predicting. 